\title{
Survey of Millimeter-Wave Propagation Measurements and Models in Indoor Environments
}

\author{
Ahmed Al-Saman ${ }^{1, *}{ }^{\oplus}$, Michael Cheffena ${ }^{1}$, Olakunle Elijah ${ }^{2} \oplus$, Yousef A. Al-Gumaei ${ }^{3}{ }^{\circledR}$, \\ Sharul Kamal Abdul Rahim ${ }^{2}$ and Tawfik Al-Hadhrami ${ }^{4}$ (D)
}

1 Department of Manufacturing and Civil Engineering, Faculty of Engineering, Norwegian University of Science and Technology (NTNU), 2815 Gjøvik, Norway; michael.cheffena@ntnu.no

2 Wireless Communication Centre, School of Electrical Engineering, Faculty of Engineering, Universiti Teknologi Malaysia, Johor Bahru 81310, Johor, Malaysia; elij_olak@yahoo.com (O.E.); sharulkamal@utm.my (S.K.A.R.)

3 Department of Computer and Information Science, Faculty of Engineering and Enviourement, Northumbria University at Newcastle, Newcastle upon Tyne NE1 8ST, UK; yousef.al-gumaei@northumbria.ac.uk

4 School of Science and Technology, Nottingham Trent University, Nottingham NG11 8NS, UK; tawfik.al-hadhrami@ntu.ac.uk

* Correspondence: ahmed.al-saman@ntnu.no

Citation: Al-Saman, A.; Cheffena, M.; Elijah, O.; Al-Gumaei, Y.A.; Abdul Rahim, S.K.; Al-Hadhrami, T. Survey of Millimeter-Wave Propagation Measurements and Models in Indoor Environments. Electronics 2021, 10 , 1653. https://doi.org/10.3390/ electronics10141653

Academic Editor: Ikmo Park

Received: 7 June 2021

Accepted: 8 July 2021

Published: 11 July 2021

Publisher's Note: MDPI stays neutral with regard to jurisdictional claims in published maps and institutional affiliations.

Copyright: (c) 2021 by the authors. Licensee MDPI, Basel, Switzerland. This article is an open access article distributed under the terms and conditions of the Creative Commons Attribution (CC BY) license (https:// creativecommons.org/licenses/by/ $4.0 /)$.

\begin{abstract}
The millimeter-wave (mmWave) is expected to deliver a huge bandwidth to address the future demands for higher data rate transmissions. However, one of the major challenges in the mmWave band is the increase in signal loss as the operating frequency increases. This has attracted several research interests both from academia and the industry for indoor and outdoor mmWave operations. This paper focuses on the works that have been carried out in the study of the mmWave channel measurement in indoor environments. A survey of the measurement techniques, prominent path loss models, analysis of path loss and delay spread for mmWave in different indoor environments is presented. This covers the mmWave frequencies from $28 \mathrm{GHz}$ to $100 \mathrm{GHz}$ that have been considered in the last two decades. In addition, the possible future trends for the mmWave indoor propagation studies and measurements have been discussed. These include the critical indoor environment, the roles of artificial intelligence, channel characterization for indoor devices, reconfigurable intelligent surfaces, and mmWave for $6 \mathrm{G}$ systems. This survey can help engineers and researchers to plan, design, and optimize reliable 5G wireless indoor networks. It will also motivate the researchers and engineering communities towards finding a better outcome in the future trends of the mmWave indoor wireless network for $6 \mathrm{G}$ systems and beyond.
\end{abstract}

Keywords: millimeter-wave propagation; radio channel; indoor environment; $28 \mathrm{GHz} ; 38 \mathrm{GHz}$; $40 \mathrm{GHz} ; 60 \mathrm{GHz} ; 70 \mathrm{GHz}$; wideband channel; 5G; 6G

\section{Introduction}

Wireless networks in an indoor environment are omnipresent, and their importance can not be underestimated in our daily lives. Radio propagation study in wireless networks in realistic indoor environments leads us to build high-density networks with large capacities. The frequency bands in the millimeter-wave (mmWave) spectrum (30-300 GHz) have gained increasing attention and now appear to be the most likely candidates to host the upcoming wireless multi-gigabit applications for $5 \mathrm{G}$ wireless networks and beyond. In this regard, the frequency range between 24.25 and $86 \mathrm{GHz}$ for the future development of International Mobile Telecommunications for 2020 and beyond has been proposed during the 2015 World Radio Communication Conference [1].

The radio channel propagation can be affected by small scattering objects due to the short wavelength of the utilized frequencies in the mmWave band. An indoor environment represents the rich sources of scattering objects for radio channel propagation. There 
are many structural issues influencing the indoor radio channel propagation, such as construction materials, building (size, rooms, corridors), number of people moving within the room, a form of furniture and location and interaction with other systems. All of these obstacles force the signal to propagate across multiple paths through reflections, refraction and diffraction phenomena. Researchers and engineers have considered this problem since the 1990s and developed myriad systems to provide channel models using path loss (PL), and wideband parameters, i.e., resolved paths and delay resolution in many different environments and frequencies.

The radio channel model can be classified into analytical models and physical models [2]. The analytic channel model is defined based on the mathematical analysis of the channel. Analytical models characterize the communication channel mathematically and can be derived from physical models such as the correlation-based Kronecker [3,4] and Weichselberger [5] channel models as well as the propagation-based finite scatterer [6], maximum entropy [7] and virtual channel representation [8] models, which are best used for algorithm development and system analysis.

The physical channel models are constructed based on the double directional radio channel between the transmitter (Tx) and Receiver (Rx) based on electromagnet wave propagation. The physical channel models can be classified into deterministic, stochastic and geometry-based stochastic. Deterministic channel models characterize the radio wave propagation in a certain physical environment based on assumptions of the propagation mechanisms. These models require a detailed geometry of the environment as well as electromagnetic parameters of the materials. The radio wave propagation is calculated by using ray-based methods or by solving Maxwell's equations [9] with full-wave methods such as the method of moments [10] or the finite difference time domain method [11]. The full-wave methods have high accuracy but they are computationally very demanding. In ray-based methods, rays are launched covering the full sphere (3D) or circle (2D) around the Tx and traced until they reach the Rx, as proposed, e.g., in [12]. Stochastic models, on the other hand, aim to describe the behaviour of the propagation channels statistically without assuming the geometry of the environment. In stochastic modeling, the parameters of the radio channel are defined by probability distribution functions, which can be tuned based on channel measurements or deterministic modeling. An example of stochastic models is the Saleh-Valenzuela model [13], which assumes that radio waves arrive to the $\mathrm{Rx}$ in concentrated groups of multipath components, called clusters. In geometry-based stochastic channel modeling (GSCM) the propagation channel from the Tx to the $\mathrm{Rx}$ is characterized deterministically but the locations and properties of the scatterer objects are chosen in a stochastic way. This approach has gained a lot of attention at lower microwave frequencies and several reference models, such as COST273 and WINNER [14], are based on GSCM. More details for physical radio channel models are found in [15]. Recently, map-based mmWave channel models proposed such as a 3-D statistical model for 5G wireless systems [16] and a backscattering channel model (Map-based) for personal radar applications [17]. More details for map-based mmWave channel models can be found in [18].

Surveys on mmWave have been identified in the literature [15,19-28]. These surveys have discussed some of the key areas that border on propagation characteristics, channel models, applications, mmWave technologies, design considerations such as environments, scenarios, and operating frequency. While some of these works have discussed measurement campaigns related to mmWave, there is still a lack of a comprehensive survey of mmWave channel measurements in indoor environments. For instance, the authors in $[24,28]$ have presented the measurement techniques and the channel models for indoor environments. There is a need for an up to date review of existing works and future directions for the mmWave communication for indoor environments.

In this work, we provide an overview of the radio propagation study at mmWave in indoor environments. Firstly, we reviewed several types of channel measurement techniques in light of the different bandwidths of the probing signal. Secondly, we have 
identified the mmWave frequencies that have been used over the last two decades in indoor environments. Third, we present the path loss model for indoor environments at mmWave bands. Fourth, the mmWave measurements result from different studies in indoor environments are discussed. Finally, the future trends and research directions are discussed.

\section{Measurement Techniques}

The most direct method of studying radio wave propagation is by channel measurements, which will achieve statistical models that verify the propagation theoretical models. Different measurement techniques with various experimental setups have been used to study the different aspects of the radio frequency (RF) channels. In general, they can be classified as narrowband (NB) and wideband (WB) techniques based on the relationship between the probing signal bandwidth and the channel coherent bandwidth.

\subsection{NB Measurement}

NB measurement techniques are used to measure the path loss, narrowband fading, small-scale fading characteristics and Doppler spread. The simplicity of this technique is the main advantage of NB measurements. In narrowband techniques, a continuous wave $(\mathrm{CW})$ is transmitted and the received power is measured over space or time. The basic block diagram of NB measurement is shown in Figure 1. The main drawback of the NB measurement technique is that the received signal represents only the envelope of the vector summation of the multipath components (MPCs); no quantitative multipath information is available. Hence, if the bandwidth of the signal is high, the WB measurement technique should be used to estimate the time dispersion parameters of the channel.

\section{Continuous Wave}

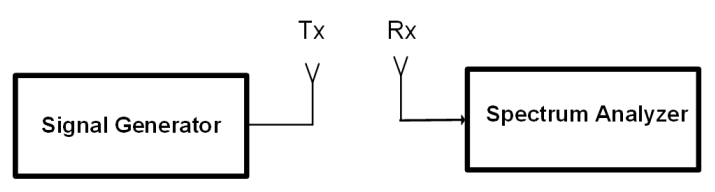

Figure 1. Narrow Band Measurement Block Diagram.

\subsection{WB Measurement}

The wideband channel sounders are used to resolve each MPC and provide the time dispersion parameters. To extract the time dispersion parameters for the wideband channel, the channel sounding measurements is applied. The wideband channel sounders are either frequency domain (WBFD) or time domain (WBTD), where the Fourier transform is used to convert between frequency and time domain.

In the frequency domain, the channel transfer function is measured using a vector network analyzer (VNA), where the complex frequency response of the channel is measured by the $S_{21}$ parameter. The block diagram for a VNA channel sounder-based system is shown in Figure 2. Using the VNA system, the channel is measured at different frequency tones along with the bandwidth of the system, by using stepped frequency sweeping. Hence, the large bandwidth results in the slower measurement of the channel. So, the VNA system can not be used to measure a time-variant channel, implying that it can be used only for slow varying channels [24,29]. 


\section{Frequency Swept}

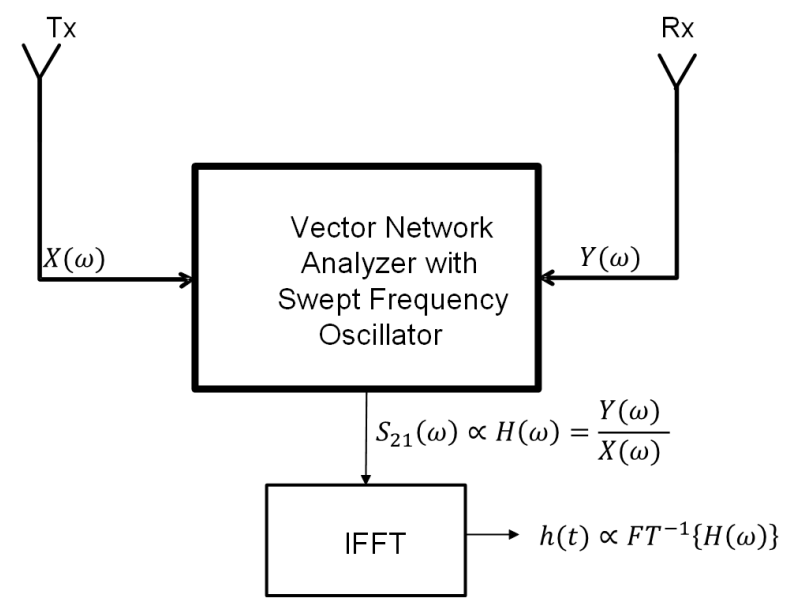

Figure 2. VNA Channel Sounder Frequency-domain Based System.

The time-domain measurement provides a more direct characterization approach. These measurement techniques use a pulse generator to transmit short pulses of the order of nano-seconds representing the large bandwidth of wideband channels, while a digital sampling oscilloscope is used to record the received signal [30-32]. This measurement technique is fast and suitable for rapid channel variations, however, it is a challenge to generate short pulses with adequate power to achieve good-quality received signals.

A more prominent measurement technique in the time domain approach uses correlation channel sounders (CS) [24,29]. In this method, a sequence of pulses such as a pseudo noise $(\mathrm{PN})$ sequence is sent by the $\mathrm{Tx}$, while in the Rx part the cross correlation between the transmitted and received signals is used to extract the channel. Since the Tx and the Rx are separated in the time domain approach, it can be used for long distance, although with a synchronization challenge. The correlation channel sounder approach is based on the assumption that the clock rate of the pulses sequence is the same at the Tx and Rx for real-time correlation processing. The wideband correlation channel sounder diagram is shown in Figure 3. It supports the fast measurement speed, which needs more expensive wideband digitizer. To use low cost narrowband digitizer with sacrifice in the measurement speed, the sliding correlation channel sounder (SCS) has been widely used, which approximates a true correlator receiver by multiplying the received signal with a "slow" copy of the transmitted signal and then filtering the product [33,34]. The block diagram of the SCS is shown in Figure 4. Although the hardware connection between the Tx and Rx is not required by the SCS measurement technique, the separation PN generators at the Tx and Rx require different references from the frequency oscillators. Moreover, the dynamic range of the measurement is restricted by the clock rate of PN sequence differences. 


\section{Wideband Correlation}

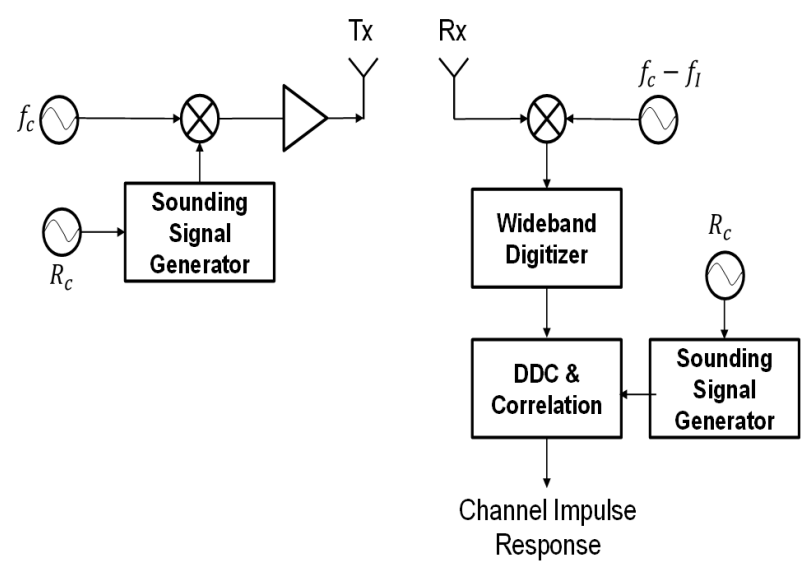

Figure 3. Wideband Correlation Channel Sounder Time-domain Based System.

\section{Sliding Correlator}

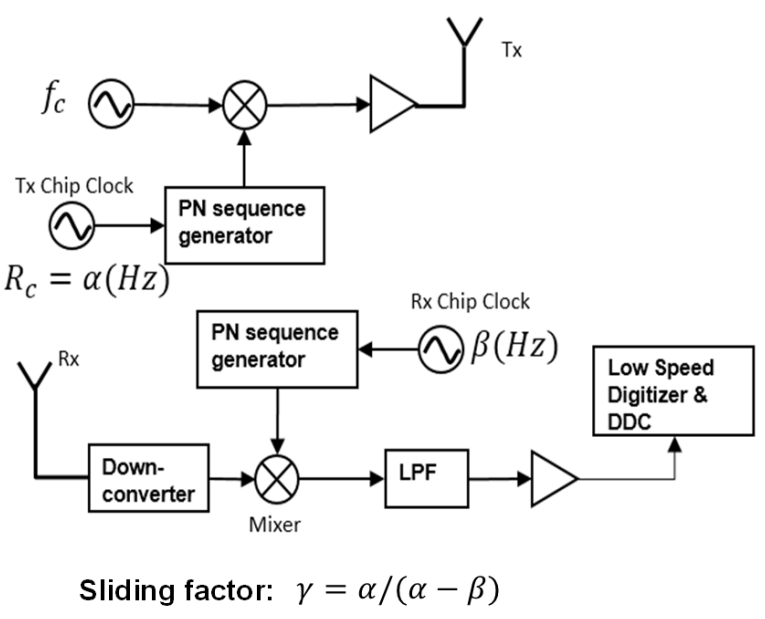

Figure 4. Sliding Correlation Channel Sounder Time-domain Based System.

\section{Mmwave Indoor Channel Characteristics}

In this section, we address indoor channel characteristics of mmWave based on path loss and time dispersion.

\subsection{Path Loss Models}

The path loss represents the fundamental quantities characterizing the wireless propagation channel and influencing the performance of any communication system. It is used to characterize the wireless channels in terms of power decay with Tx-Rx separation distance. Extensive studies have been done to investigate the indoor channel models for mmWave in terms of path loss. Different path loss models have been proposed and investigated for the indoor channels at different mmWave bands, including the close-in free space reference distance (CI) model as well as the 3GPP and WINNER floating intercept (FI) model. The path loss model estimates the amount of degradation on the propagated signals along the propagation path with a certain distance for line-of-sight (LOS) and non-LOS (NLOS) 
channels. The reflection, refraction, diffraction, and scattering are considered in path loss evaluation. The CI path loss model is expressed as [35]:

$$
P L^{C I}(f, d)[d B]=P L\left(f, d_{0}\right)+10 n \log _{10}\left(d / d_{0}\right)+X_{\sigma},
$$

where $P L(f, d)$ is the path loss at different frequencies with various $\mathrm{Tx}$ - $\mathrm{Rx}$ separation distance ( $d$ in meters), $P L\left(f, d_{0}\right)$ is the path loss at close-in reference distance $d_{0}$ in $\mathrm{dB}, n$ denotes the distance dependency of path loss and called path loss exponent (PLE), and $X_{\sigma}$ is a zero-mean Gaussian distributed random variable with a standard deviation $\sigma \mathrm{dB}$ (shadowing effects). The FI path loss model is defined as [35]:

$$
P L^{F I}(d)[d B]=\alpha+10 \cdot \beta \log _{10}(d)+X_{\sigma}{ }^{F I},
$$

where $\alpha$ and $\beta$ are the floating-intercept in $\mathrm{dB}$ and the slope of the line, respectively. The shadow fading is represented by zero mean Gaussian random variable $X_{\sigma}{ }^{F I} \mathrm{~dB}$ with standard deviation of $\sigma \mathrm{dB}$.

Another popular model is the ABG path loss model, which is well-used to investigate frequency dependency of path loss besides distance dependency in FI model. Recently, the ABG model is widely used in mmWave band for $5 \mathrm{G}$ system and it is defined as [36]:

$$
\begin{aligned}
P L^{A B G}(f, d)[d B]= & 10 \alpha \log _{10}(d)+\beta \\
& +10 \gamma \log 10(f / 1 \mathrm{GHz})+X_{\sigma}{ }^{A B G},
\end{aligned}
$$

where $\alpha$ is the distance dependence factor on path loss, $\beta$ is an optimized offset, $\gamma$ is the frequency dependence factor and $X_{\sigma}{ }^{A B G}$ is the shadow fading term. The close-in free space reference distance model with frequency-dependent PLE (CIF) is recently proposed to model the propagation loss for indoor channels in the mmWave for the 5G system. It is presented as [37]:

$$
\begin{aligned}
P L^{C I F}= & P L\left(f, d_{0}\right)+10 n\left(1+b\left(\frac{f-f_{0}}{f_{0}}\right)\right) \log _{10}\left(d / d_{0}\right) \\
& +X_{\sigma}
\end{aligned}
$$

where $n$ denotes PLE, and $b$ is an optimization parameter that captures the slope, or linear frequency dependency of the PLE that balances at the centroid of the frequencies being modeled. The term $f_{0}$ is a fixed reference frequency, the centroid of all frequencies represented by the path loss model, found as the weighted sum of measurements from different frequencies, using the following equation:

$$
f_{0}=\frac{\sum_{k=1}^{K} f_{k} N_{K}}{\sum_{k=1}^{K} N_{K}},
$$

where $K$ is the number of unique frequencies, and $N_{k}$ is the number of path loss data points correspondings to the $k$ th frequency $f_{k}$. The input parameter $f_{0}$ represents the weighted frequencies of all measurement (or Ray-tracing) data applied to the model. For large indoor distances (greater than $50 \mathrm{~m}$ ), the breakpoint at a specific distance $\left(d_{B p}\right)$ was used and the dual-slope ABG and CIF models were considered [38].

\subsection{Time Dispersion Parameters}

The root mean square delay spread (RMSDS) is used to characterize the time dispersion properties of the wideband channel. It is an indicator of the possible extent of inter-symbol interference according to the bandwidth of the signal [39]. It is defined as the second central moment of the power delay profile (PDP) [40]:

$$
\tau_{r m s d s}=\sqrt{\overline{\tau^{2}}-(\bar{\tau})^{2}},
$$


where,

$$
\begin{aligned}
\bar{\tau} & =\frac{\sum_{l} P\left(\tau_{l}\right) \tau_{l}}{\sum_{l} P\left(\tau_{l}\right)}, \\
\overline{\tau^{2}} & =\frac{\sum_{l} P\left(\tau_{l}\right) \tau_{l}^{2}}{\sum_{l} P\left(\tau_{l}\right)},
\end{aligned}
$$

The (7) and (8) represent the first moment (mean excess delay) and second moment of the PDP, respectively. The $P\left(\tau_{l}\right)$ is the received power at $l$ th multipath.

\section{Review of mmWave Indoor Measurements}

In this section, a review of published work on the mmWave frequencies that have been used in different indoor environments is discussed.

The 30-300 GHz spectrum is assigned to the extremely high frequency (EHF) or mmWave band, however, the industry often uses the term mmWave to define frequencies between $10 \mathrm{GHz}$ and $300 \mathrm{GHz}$ [41]. Here, we will include the $28 \mathrm{GHz}$ in mmWave band as it is near the EHF spectrum and it has been used for many studies in indoor environments. The $28 \mathrm{GHz}$ was used for indoor environments recently (since 2013) for 5G wireless networks. Many researchers have investigated radio propagation at mmWave band for different scenarios in various indoor environments in both LOS and NLOS scenarios.

The measurements were conducted at different frequencies from $28 \mathrm{GHz}$ to $100 \mathrm{GHz}$. Different antennas with different gains and half-power beamwidths (HPBWs) in azimuth $(\mathrm{Az})$ or elevation $(\mathrm{Ev})$ plane were used. Some of those antennas are directional such as horn antennas or omnidirectional (Omni) such as biconical and open-ended waveguide (OEW) antennas.

Tables 1-5 give a comprehensive overview of published indoor mmWave channel measurement campaigns in the last two decades from different regions in the world. The tables describe the measurement scenario either LOS or NLOS or both LOS and NLOS, measurement region, the measurement technique types, center frequency, the delay resolution of wideband measurements that represented by inverse of radio frequency bandwidth (B), the antenna type, gain, and HPBW, the Tx-Rx separation distance, and the studied parameters. The reported indoor measurement campaigns in the literature were taken in the indoor office, corridor, hall, different type of rooms (conference, meeting, computer, class, living, dining, empty, and others), laboratory, shopping mall, library, tunnel, courtyard, lobby, railway station, and airport.

\begin{tabular}{|c|c|c|c|c|c|c|c|c|}
\hline Source & $\begin{array}{c}\text { Scenarios } \\
\text { LOS, NLOS }\end{array}$ & Region & $\begin{array}{l}\text { Meas. } \\
\text { Type }\end{array}$ & $\begin{array}{c}\text { Frq. (GHz) } \\
\quad / \frac{1}{B} \text { (ns) }\end{array}$ & $\begin{array}{l}\text { Antenna Type } \\
\text { /Gain (dBi) }\end{array}$ & $\begin{array}{l}\text { AzHPBW }\left(^{\circ}\right) \\
/ \operatorname{EvHPBW}\left({ }^{\circ}\right)\end{array}$ & $\begin{array}{l}\text { Distance } \\
\text { (m) }\end{array}$ & Channel Statistics \\
\hline [37] & Both & USA & WBTD & $28 / 2.5$ & Horn $/ 20$ & $15 / 15$ & $4-46$ & $\begin{array}{l}\text { PL, PDP, } \\
\text { RMSDS }\end{array}$ \\
\hline [42] & Both & China & WBTD & $28 / 2$ & Horn/- & $10 /-$ & - & RMSDS, AOA, AS \\
\hline [43] & Both & South Korea & WBTD & $28 / 4$ & Horn $/ 24.5$ & $10 / 10$ & $10-40$ & PL,AS, RMSDS \\
\hline [44] & Both & China & WBTD & $28 / 4$ & Omni & - & $1-45$ & PL, RMSDS \\
\hline [45] & Both & China & WBTD & $28 /-$ & Horn & $2-$ & - & PL \\
\hline [46] & Both & China & WBFD & $28 / 1$ and 0.5 & Horn/19.2 & $20 / 18$ & $<20$ & PL \\
\hline [47] & Both & New Zealand & WBTD & $28 / 1.7$ & $\begin{array}{c}\text { Biconical, Sectored, } \\
\text { Horn/2.4, 9.4, } 25\end{array}$ & $\begin{array}{c}360,92.2 \\
\text { and } 10\end{array}$ & $<50$ & $\begin{array}{l}\text { PL,RMSDS, } \\
\text { AS, K-factor }\end{array}$ \\
\hline$[48]$ & Both & - & WBFD & $28 / 1$ & Omni, Horn/6, 25 & $10 / 10$ & - & PDP, AOA \\
\hline [49] & LOS & China & WBTD & $28 / 2$ & Omni, Horn/8, 25 & - & $1-30$ & PL, RMSDS \\
\hline
\end{tabular}

Table 1. MmWave channel measurement in indoor offices. 
Table 1. Cont.

\begin{tabular}{|c|c|c|c|c|c|c|c|c|}
\hline Source & $\begin{array}{c}\text { Scenarios } \\
\text { LOS, NLOS }\end{array}$ & Region & $\begin{array}{l}\text { Meas. } \\
\text { Type }\end{array}$ & $\begin{array}{c}\text { Frq. (GHz) } \\
/ \frac{1}{B} \text { (ns) }\end{array}$ & $\begin{array}{l}\text { Antenna Type } \\
\text { /Gain (dBi) }\end{array}$ & $\begin{array}{l}\text { AzHPBW }\left(^{\circ}\right) \\
/ \text { EvHPBW }\left(^{\circ}\right)\end{array}$ & $\begin{array}{l}\text { Distance } \\
\quad(\mathrm{m})\end{array}$ & Channel Statistics \\
\hline [50] & LOS & South Korea & WBTD & $28 / 2$ & Horn $/ 24.5$ & 10 & $5-14$ & $\begin{array}{l}\text { PL,AS, } \\
\text { RMSDS }\end{array}$ \\
\hline [51] & Both & Denmark & WBFD & $26-30 / 0.25$ & horn $/ 6,19$ & $20 / 20$ & $5-$ & PL, PAPD \\
\hline [52] & LOS & USA & WBFD & $26.5-40 / 0.07$ & Horn $/ 10$ & $-/ 55$ & $0.2-1.8$ & PL \\
\hline [53] & - & China & NB & 28 and 31 & Horn & - & - & Penetration loss \\
\hline [54] & Both & South Korea & WBTD & 28 and $38 / 2$ & Omni/5 and 6 & - & $6-54$ & PL \\
\hline [55] & LOS & UK & WBTD & 32 and $39 / 0.5$ & Horn/10 & $54 / 54$ & $4-20$ & PL, RMSD \\
\hline [56] & LOS & Japan & NB & 37.1 & Horn, Omni/- & $-/ 60$ & $5-45$ & PL \\
\hline [57] & Both & China & NB & 45 & $\begin{array}{c}\text { Horn,OEW, } \\
\text { VDA / } 23.7,6,2.5\end{array}$ & $\begin{array}{l}12,60,120 \\
/ 12,60,240\end{array}$ & $1-10$ & $\begin{array}{c}\text { PL } \\
\text { shadow fading }\end{array}$ \\
\hline [29] & Both & Germany & WBTD & $60 / 1,0.2$ & Omni & - & $0.5-10$ & PL, RMSDS \\
\hline$[58,59]$ & Both & USA & WBTD & $60 / 2.5$ & Horn $/ 25$ & $50 / 50$ & $3.5-24.7$ & PL, RMSDS \\
\hline$[60,61]$ & Both & Germany & WBTD & $60,70 / 0.25$ & Horn and Lens / 20 & $15 / 15$ & - & $\begin{array}{l}\text { AOD, RMSD, } \\
\text { PDP }\end{array}$ \\
\hline [62] & Both & Japan & WBFD & $70 / 0.33$ & Horn, Omni/-/- & $15,30,60 /-$ & $4-19$ & PL \\
\hline$[37,63,64]$ & Both & USA & WBTD & $73.5 / 2.5$ & Horn $/ 20$ & $15 / 15$ & $4-42$ & $\begin{array}{l}\text { PL, PDP, } \\
\text { RMSDS }\end{array}$ \\
\hline$[65,66]$ & LOS & Finland & WBFD & $\begin{array}{c}61-65,69-74 \\
/ 0.25,0.2\end{array}$ & Omni, Horn/5, 20 & $20 / 20$ & $0.9-10.3$ & Scattering \\
\hline [67] & Both & China & WBTD & $60 / 0.5$ & Horn $/ 25$ & $10 / 10$ & $2-6$ & $\begin{array}{l}\text { AS, PDP, } \\
\text { PAS }\end{array}$ \\
\hline [68] & Both & Austria & WBFD & $55-65 / 0.1$ & OEW /5 & - & $2.5-3$ & CIR \\
\hline$[69,70]$ & LOS & France & WBFD & $60 / 0.5$ & Omni, Horn / 2, 22.5 & $13 / 10$ & - & PL, CIR \\
\hline
\end{tabular}

\subsection{Indoor Office}

The office environment is characterized by obstructions from different objects such as desks, chairs, cubicle partitions, doors, windows, and walls. Measurement set-ups are positioned at heights above ground levels (AGL) such as $1.80 \mathrm{~m}$ [45] and $1.48 \mathrm{~m} \mathrm{[46].} \mathrm{A}$ review of the works in indoor offices environment at different frequencies are presented as follows.

Based on directional measurements at $28 \mathrm{GHz}$ using horn antennas in indoor offices environments [37] the path loss (PL) results showed that the PLE values are 1.7 and 4.4 for LOS and NLOS scenarios, respectively. It was observed that when the polarization of the Tx and Rx antennas are different (cross-polarization) such as vertical-horizontal $(\mathrm{V}-\mathrm{H})$, the PLEs for the same particular scenario are 4.1 and 5.1 for LOS and NLOS scenarios, respectively. This implies that the received power significantly degrades when the polarization of the $\mathrm{Rx}$ antenna is different from the Tx antenna polarization. For the directional channel characteristics using horn antennas at Tx and Rx, the AzHPBW and EvHPBW of the antennas are crucial for power delay profile (PDP) and the PL statistics. Hence, to get the accurate channel statistics for such an environment using horn antennas that have high gains, the horn antennas are usually installed on a rotational platform to collect the signals from different directions. The Tx and Rx horn antennas should be rotated to different angles where the total received power obtained by summing the received powers at each steering direction [37] Large scale omnidirectional path loss models were developed based on this concept as presented in [37] for both LOS and NLOS scenarios. It was shown that the omnidirectional PLE values at $28 \mathrm{GHz}$ are 1.1 and 2.7 for LOS and NLOS scenarios, respectively. This implies that the received power significantly improved for both scenarios when the rotation platform was used. The same results were reported in $[46,50]$ the omnidirectional PLE values based on directional measurements with rotation 
platform are 1.6 and 2.1 for LOS and NLOS scenarios, respectively. Based on measurements using omnidirectional antennas at both Tx and $\mathrm{Rx}$ [54] it was found that the PLE values are 1.8 and 3.0 for LOS and NLOS scenarios, respectively. Some of the measurements used omnidirectional antenna in one side only either in Tx or Rx and used a horn antenna on the other side. In [49], it was found that the PLE for the LOS scenario at $28 \mathrm{GHz}$ is $1.7 \mathrm{using}$ omnidirectional antenna at $\mathrm{Tx}$ and horn antenna at Rx. The same observations for the effects of antenna types were found at $60 \mathrm{GHz}$ band and $70 \mathrm{GHz}$ band in different indoor office environments.

Table 2. MmWave channel measurement in different rooms and halls.

\begin{tabular}{|c|c|c|c|c|c|c|c|c|}
\hline Source & $\begin{array}{c}\text { Scenarios } \\
\text { LOS, NLOS }\end{array}$ & Region & $\begin{array}{l}\text { Meas. } \\
\text { Type }\end{array}$ & $\begin{array}{l}\text { Frq. (GHz) } \\
\qquad / \frac{1}{B}(\mathrm{~ns})\end{array}$ & $\begin{array}{l}\text { Antenna Type } \\
\text { /Gain (dBi) }\end{array}$ & $\begin{array}{l}\text { AzHPBW }\left({ }^{\circ}\right) \\
/ \operatorname{EvHPBW}\left({ }^{\circ}\right)\end{array}$ & $\begin{array}{l}\text { Distance } \\
\text { (m) }\end{array}$ & Channel Statistics \\
\hline [71] & $\begin{array}{l}\text { Dining room } \\
\text { LOS }\end{array}$ & Malaysia & WBTD & $28,38 / 1$ & $\begin{array}{l}\text { omni, horn } \\
/ 3,19.2,21.1\end{array}$ & $18.6,14.5 /-$ & $1-10$ & PL, RMSDS \\
\hline$[72]$ & Rooms (NLOS) & USA, Chile & NB & $28 /-$ & Horn/10, 24 & $55,10 /-$ & $<100$ & PL \\
\hline [73] & $\begin{array}{c}\text { Conference room } \\
\text { Both }\end{array}$ & China & WBFD & $28 /-$ & Horn $/ 20$ & $17 / 14.6$ & $1-10$ & PL \\
\hline [74] & $\begin{array}{l}\text { Empty room } \\
\text { Both }\end{array}$ & Denmark & WBFD & $\begin{array}{l}28-30 / 0.50 \\
26-30 / 0.25\end{array}$ & $\begin{array}{l}\text { Biconical, } \\
\text { horn } / 6,19\end{array}$ & $20 / 20$ & - & PL, PAPD \\
\hline [75] & $\begin{array}{l}\text { Computer room } \\
\text { Both }\end{array}$ & China & WBTD & $\begin{array}{c}30,60 \\
/ 0.45,0.9\end{array}$ & Horn $/ 15,20$ & 35 & 28 & PDP, RMSDS \\
\hline [57] & $\begin{array}{c}\text { Conference, } \\
\text { living rooms (Both) }\end{array}$ & China & NB & $45 /-$ & $\begin{array}{c}\text { Horn,OEW, } \\
\text { VDA } / 23.7,6,2.5\end{array}$ & $\begin{array}{l}12,60,120 \\
/ 12,60,240\end{array}$ & $1-10$ & $\begin{array}{c}\text { PL } \\
\text { shadow fading }\end{array}$ \\
\hline [76] & Classrooms (Both) & Malaysia & NB & $40 /-$ & $\begin{array}{l}\text { Horn, Omni } \\
/ 21.34,3\end{array}$ & - & $1-27$ & PL \\
\hline [77] & $\begin{array}{l}\text { Conference room } \\
\text { LOS }\end{array}$ & China & WBTD & $39 / 0.5$ & Horn, Omni & - & $2-10$ & $\begin{array}{l}\text { PL, RMSDS, } \\
\text { K-factor }\end{array}$ \\
\hline [78] & $\begin{array}{l}\text { Conference room } \\
\text { Both }\end{array}$ & China & WBFD & $45 / 1.5$ & Horn/18.9, 23.7 & $11,18.2$ & - & PDP, AOA \\
\hline [79] & Rooms (Both) & USA & WB & $60 / 10$ & OEW, horn/6.7, 29 & 90,7 & $2.4-60$ & $\begin{array}{l}\text { PL, RMSDS, } \\
\text { PAP }\end{array}$ \\
\hline$[80]$ & $\begin{array}{c}\text { Conference room } \\
\text { LOS }\end{array}$ & Germany & WBTD & $60 / 1$ & Omni/2 & $-/ 70$ & $1-5$ & $\begin{array}{l}\text { PL, RMSDS, } \\
\text { PDP }\end{array}$ \\
\hline$[81,82]$ & Rooms (Both) & Russia & WBTD & $60 / 1.3$ & Horn/16, 18 & 25,20 & $<3$ & Polarization \\
\hline [83] & $\begin{array}{l}\text { Computer room } \\
\text { LOS }\end{array}$ & France LOS & WBFD & $60 / 0.5$ & Polarized/12, 10 & $30 / 30$ & $1-7$ & PL, Fading \\
\hline$[84]$ & Room (Both) & Netherlands & WBFD & $60 / 0.5$ & Biconical/9/- & 9 & $0.7-7$ & PL \\
\hline [85] & $\begin{array}{l}\text { Empty room } \\
\text { LOS }\end{array}$ & USA & WBFD & $60 / 2.5$ & bow-tie & - & - & RMSDS, fading \\
\hline [86] & $\begin{array}{l}\text { Conference room } \\
\text { Both }\end{array}$ & Finland & WBFD & $61-65 / 0.25$ & Biconical, OEW & - & - & $\mathrm{AOD}, \mathrm{AOA}$ \\
\hline [87] & Room (Both) & Netherlands & WBFD & $58 / 0.5$ & Omni /- & - & $0.5-14$ & PL, RMSDS \\
\hline [88] & Rooms (Both) & Japan & WBFD & $61-65 / 0.25$ & Bioconical, OEW /2, 7 & - & $1-5$ & PL, RMSDS \\
\hline [89] & $\begin{array}{c}\text { Conference room } \\
\text { LOS }\end{array}$ & Germany & WBTD & $60 / 0.33$ & Omni, OEW /2, 8 & - & $2-10$ & $\begin{array}{c}\text { Human body } \\
\text { shadowing effects }\end{array}$ \\
\hline$[69,70]$ & $\begin{array}{l}\text { Meeting room } \\
\text { LOS }\end{array}$ & France & WBFD & $60 / 0.5$ & Omni, Horn/ 2, 22.5 & $13 / 10$ & - & PL, CIR \\
\hline$[90]$ & Rooms (Both) & UK & WBFD & $57-64 / 1$ & Omni/6 & - & - & PDP ,RMSDS \\
\hline$[91,92]$ & $\begin{array}{c}\text { Class rooms, } \\
\text { hall (Both) }\end{array}$ & Denmark & WBFD & $28 / 0.5$ & Bicone/4.8, 6 & - & $2.5-6.5$ & $\begin{array}{l}\text { PL,AS, } \\
\text { RMSDS }\end{array}$ \\
\hline [93] & Halls (Both) & UAE & NB & $28 /-$ & Horn/15 & - & $1-60$ & PL \\
\hline
\end{tabular}


Table 3. MmWave channel measurement in indoor corridors/ hallways.

\begin{tabular}{|c|c|c|c|c|c|c|c|c|}
\hline Source & $\begin{array}{c}\text { Scenarios } \\
\text { LOS, NLOS }\end{array}$ & Region & $\begin{array}{l}\text { Meas. } \\
\text { Type }\end{array}$ & $\begin{array}{c}\text { Frq. (GHz) } \\
\quad / \frac{1}{B} \text { (ns) } \\
\end{array}$ & $\begin{array}{c}\text { Antenna Type } \\
\text { /Gain (dBi) }\end{array}$ & $\begin{array}{l}\text { AzHPBW }\left({ }^{\circ}\right) \\
/ \operatorname{EvHPBW}\left({ }^{\circ}\right)\end{array}$ & $\begin{array}{l}\text { Distance } \\
\text { (m) }\end{array}$ & Channel Statistics \\
\hline$[35,36,94]$ & Both & Malaysia & WBTD & $28,38 / 1$ & $\begin{array}{l}\text { Omni, horn } \\
/ 3,11.6,15.2\end{array}$ & $\begin{array}{l}37.6,27.5 \\
/ 44.8,28.3\end{array}$ & $1-67$ & $\begin{array}{l}\text { PL, AS, } \\
\text { RMSDS }\end{array}$ \\
\hline [72] & NLOS & $\begin{array}{l}\text { USA, } \\
\text { Chile }\end{array}$ & NB & $28 /-$ & Horn/10, 24 & $55,10 /-$ & $<100$ & PL \\
\hline [46] & Both & China & WBFD & $28 / 1$ and 0.5 & Horn/19.2 & $20 / 18$ & $<20$ & PL \\
\hline [95] & Both & China & WBTD & $28 / 1$ & Omni/5 & - & $3-20$ & $\begin{array}{l}\text { PL, RMSDS, } \\
\text { K-factor }\end{array}$ \\
\hline [93] & LOS & UAE & NB & $28 /-$ & Horn/15 & - & $1-60$ & PL \\
\hline$[96,97]$ & LOS & USA & NB & $30 /-$ & Omni & - & $\begin{array}{l}1-6.5 \\
8-13.5\end{array}$ & PL \\
\hline [98] & Both & USA & NB & 31 & Horn $/ 10$ & $54 / 54$ & $\begin{array}{l}1-67 \\
18-25\end{array}$ & PL \\
\hline [99] & Both & Germany & WBTD & $30 /-$ & Horn/- & 30 & $10-80$ & $\begin{array}{l}\text { PL, RMSDS, } \\
\text { PDP }\end{array}$ \\
\hline [76] & Both & Malaysia & NB & $40 /-$ & $\begin{array}{l}\text { Horn, Omni } \\
/ 21.34,3\end{array}$ & - & $1-27$ & PL \\
\hline [100-102] & Both & Spain & WBFD & $\begin{array}{c}30,39 \text {, and } \\
40 / 0.026\end{array}$ & Omni & - & $0.5-13$ & $\begin{array}{l}\text { PL, K-factor, } \\
\text { RMSDS }\end{array}$ \\
\hline [103] & Both & China & WBTD & $41 / 0.5$ & Horn $/ 24$ & $7 / 7$ & $1.35-70$ & PL, RMSDS \\
\hline [104] & LOS & Greece & WBTD & $60 / 8$ & Horn/21 & $36 / 11$ & - & RMSDS \\
\hline [105] & LOS & Germany & WBTD & $60 / 1$ & OEW, lens & $6 / 120 /-$ & - & $\begin{array}{c}\text { PAP, PDP, } \\
\text { K-factor, RMSDS }\end{array}$ \\
\hline$[90]$ & - & UK & WBFD & $57-64 / 1$ & $\begin{array}{l}\text { Omni, horn } \\
/ 6,10,10\end{array}$ & $-, 69,55 / 6.5,-,-$ & - & PDP , RMSDS \\
\hline$[99,106]$ & Both & Germany & WBTD & 60 and $74 /-$ & Horn $/ 20$ & 30,15 & $10-80$ & $\begin{array}{l}\text { PL, RMSDS, } \\
\text { PDP, AS }\end{array}$ \\
\hline [107] & LOS & Spain & WBTD & $39 / 7.1$ & Horn, Omin/20.9, 3.5 & 14,26 & $5-50$ & PL \\
\hline [79] & Both & USA & WB & $60 / 10$ & OEW, horn/6.7, 29 & 90,7 & $2.4-60$ & $\begin{array}{l}\text { PL, RMSDS, } \\
\text { PAP }\end{array}$ \\
\hline
\end{tabular}

Table 4. MmWave channel measurement in laboratories.

\begin{tabular}{|c|c|c|c|c|c|c|c|c|}
\hline Source & $\begin{array}{c}\text { Scenarios } \\
\text { LOS, NLOS }\end{array}$ & Region & Meas.Type & $\begin{array}{l}\text { Frq. (GHz) } \\
\qquad / \frac{1}{B} \text { (ns) }\end{array}$ & $\begin{array}{l}\text { Antenna Type } \\
\text { /Gain (dBi) }\end{array}$ & $\begin{array}{l}\text { AzHPBW }\left({ }^{\circ}\right) \\
/ \operatorname{EvHPBW}\left({ }^{\circ}\right)\end{array}$ & $\begin{array}{l}\text { Distance } \\
(\mathrm{m})\end{array}$ & Channel Statistics \\
\hline [93] & Both & UAE & NB & $28 /-$ & Horn/15 & - & $1-60$ & PL \\
\hline$[96,97]$ & Both & USA & NB & 30 & Omni & - & $\begin{array}{l}1-6.5 \\
8-13.5\end{array}$ & PL \\
\hline [108] & - & Hungary & NB & 38 & Horn & - & $1-36$ & RSS \\
\hline [100-102] & Both & Spain & WBFD & $\begin{array}{c}30,39 \text {, and } \\
40 / 0.026\end{array}$ & Omni & - & $0.5-13$ & $\begin{array}{l}\text { PL, K-factor, } \\
\text { RMSDS }\end{array}$ \\
\hline [109] & - & China & NB & 45 & Horn $/ 25$ & 10 & 8.5 & Diffraction \\
\hline [110] & Both & France & WBTD & $60 / 2$ & Horn, patch/22.4, 3 & $12,60 / 10,60$ & $8.7-13.2$ & Human effects \\
\hline [29] & Both & Germany & WBTD & $60 / 1,0.2$ & Omni & - & $0.5-10$ & PL, RMSDS \\
\hline [111] & Both & Greece & NB & 60 & Horn/21 & $36 / 11$ & $0.5-15$ & $\begin{array}{l}\text { PL, Fading statistics, } \\
\text { people effect }\end{array}$ \\
\hline [104] & Both & Greece & WBTD & $60 / 8$ & Horn/21 & $36 / 11$ & - & RMSDS, excess delay \\
\hline
\end{tabular}


Table 5. MmWave channel measurement in indoor libraries and other indoor environments.

\begin{tabular}{|c|c|c|c|c|c|c|c|c|}
\hline Source & $\begin{array}{c}\text { Scenarios } \\
\text { LOS, NLOS }\end{array}$ & Region & $\begin{array}{l}\text { Meas. } \\
\text { Type }\end{array}$ & $\begin{array}{c}\text { Frq. (GHz) } \\
/ \frac{1}{B} \text { (ns) } \\
\end{array}$ & $\begin{array}{l}\text { Antenna Type } \\
\text { /Gain (dBi) }\end{array}$ & $\begin{array}{l}\text { AzHPBW }\left(^{\circ}\right) \\
/ \operatorname{EvHPBW}\left({ }^{\circ}\right)\end{array}$ & $\begin{array}{l}\text { Distance } \\
\text { (m) }\end{array}$ & Channel Statistics \\
\hline [112] & Library (Both) & USA & WBTD & $28 / 0.5$ & Horn/17 & $24 / 26$ & $10-50$ & $\begin{array}{l}\text { PADP, PL, } \\
\text { RMSDS }\end{array}$ \\
\hline [29] & Library (Both) & Germany & WBTD & $60 / 1,0.2$ & Omni & - & $0.5-10$ & PL, RMSDS \\
\hline [77] & Lobby (LOS) & China & WBTD & $39 / 0.5$ & Horn, Omni & - & $2-10$ & $\begin{array}{l}\text { PL, RMSDS, } \\
\text { K-factor }\end{array}$ \\
\hline [98] & Courtyard & USA & NB & 31 & Horn/10 & $54 / 54$ & $\begin{array}{l}1-67 \\
18-25\end{array}$ & PL \\
\hline [113] & Shopping mall (LOS) & China & WBTD & $28 / 0.833$ & Horn $/ 25$ & $10 / 11$ & - & $\begin{array}{c}\text { Human } \\
\text { shadowing }\end{array}$ \\
\hline [114] & Shopping mall (Both) & Finland & WBFD & $28 / 0.25$ & $\begin{array}{c}\text { Horn, bicone } \\
/ 19,0\end{array}$ & $10 / 40,60$ & $<35$ & PL \\
\hline$[65,66]$ & $\begin{array}{c}\text { Shopping mall } \\
\text { railway station (LOS) }\end{array}$ & Finland & WBFD & $\begin{array}{c}61-65,69-74 \\
/ 0.25,0.2\end{array}$ & Omni, Horn/5, 20 & $20 / 20$ & $0.9-10.3$ & Scattering \\
\hline [93] & Tunnel (Both) & UAE & NB & $28 /-$ & Horn/15 & - & $1-60$ & PL \\
\hline [115] & $\begin{array}{l}\text { Indoor airport } \\
\text { terminal (Both) }\end{array}$ & USA & NB & 31 & Horn/10 & $54 / 54$ & $2-14$ & PL \\
\hline$[116,117]$ & $\begin{array}{l}\text { Indoor airport } \\
\text { terminal (Both) }\end{array}$ & $\begin{array}{l}\text { South } \\
\text { Korea }\end{array}$ & WBTD & 2 & Horn/10 and 24.4 & $/ 60$ and 10 & $28-300$ & PL \\
\hline
\end{tabular}

The RMSDS, Angle of arrival (AOA), Angle of departure (AOD) and angular spread (AS) were investigated in $[42,43,47,50]$ at $28 \mathrm{GHz}$ and in $[60,61]$ at 60 and $70 \mathrm{GHz}$, based on WBTD measurements using horn antennas at both Tx and Rx sides. The channel impulse response (CIR), power angular profile (PAP), power angular spread (PAS), power angular and delay profile (PADP) and K-factor channel statistics were presented in different indoor office environments at various mmWave frequencies. Table 1 summarizes a comparison of mmWave channel measurements for indoor office environments.

\subsection{Indoor Room, Hall, and Hallway/Corridor}

The halls are characterized by large spaces and sometimes limited objects. The rooms are characterized by smaller spaces and more objects. Corridors are usually long passages in a building from which doors lead into rooms.

The study from $[91,92]$ has shown that the size of the hall and position of the Tx and $R x$ can affect the delay spread and the angle spread. Higher values of delay spread were obtained in hall compared to the smaller environment like the classroom and office but with lower angle spread. Wei et al. [74] compared the spatial-temporal characteristics of 28-30 GHz to other frequencies 2-4, 14-16 GHz in LOS and obstructed-LOS scenarios in an empty room. The results show the $28-30 \mathrm{GHz}$ has similar PADP with the $14-16 \mathrm{GHz}$, however, a richer multipath environment was obtained at $2-4 \mathrm{GHz}$ due to diffuse scattering effects. Furthermore, few scatters were observed at $28-30 \mathrm{GHz}$ in the empty room which indicated the lack of frequency dependency.

A comparative study of measurement versus ray tracing simulation using PAP was presented for large empty room and office scenarios [51]. The results of the empty room scenario from the measurements and simulations were in agreement and characterized by sparse delay and angle domains, with only a few dominant paths. In [75], a wideband measurement for indoor environment with tables, computers and enclosed with glass windows and a room was reported for $30 \mathrm{GHz}$. An RMSDS of $28 \mathrm{~ns}$ at 95\% CDF value was obtained for dual polarized antennas with the Tx positioned at $2.35 \mathrm{~m}$ AGL and the Rx at 1.6 m AGL in a near LOS scenario. In [71], directional and omni-directional large-scale path loss models were investigated in a dining room for $28 \mathrm{GHz}$ and compared with $38 \mathrm{GHz}$. It was observed that the location of the Rx and the density of the surrounding objects in room can affect the RMSDS and PL. Smaller RMSDSs were noticed in LOS boresight locations 
compared to gypsum board and glass window locations due to less obstruction and multipath effects. In [77], the study for large scale and small scale propagation characteristics for $39 \mathrm{GHz}$ was carried out in a conference room and lobby. The results from the lobby indicated rich MPCs, greater values of RMSDS and RMS AS when compared to the 3GPP channel model. The summary of a comparison of mmWave channel measurements for indoor rooms and hall environments is given in Table 2.

The experimental results in [72] showed that the propagation link between the corridors and rooms was affected due to the penetration loss. For instance, a $12 \mathrm{~dB}$ loss was observed in the $28 \mathrm{GHz}$ compared to the $2 \mathrm{GHz}$ in the same corridor. In [35,36], the CI and FI path-loss models were investigated using the $\mathrm{V}-\mathrm{V}$ and $\mathrm{V}-\mathrm{H}$ antenna polarizations. The PLEs for the V-V and V-H configurations obtained for the corridors were less than 2. It was observed that the MPCs added up constructively due to the side walls along the corridor. A comparative study of $28 \mathrm{GHz}$ and $3.5 \mathrm{GHz}$ was conducted in [94] and the diffraction loss (DL) and frequency drop (FD) were investigated. It was observed that the DL for the $28 \mathrm{GHz}$ was twice that of the $3.5 \mathrm{GHz}$. The Path loss and small-scale fading were investigated in [96] using directional antennas at $30 \mathrm{GHz}$ in a LOS scenario on the corridor. The strength of the direct path signal was used to determine the coefficients $K$ and $m$ that best fit the Rician and Nakagami distribution models, respectively. A Good fit of the model was obtained from the computation of the measured data but the values $K$ and $m$ are affected by the distance between Tx and Rx. However, the Rician factor $K$ was computed by trial-and-error, while the Nakagami factor $m$ was directly computed from the measured data. The modified-CI model offered the same PLE as FI model with less computational complexity. In [103], the propagation characteristic in a confined corridor with a corner was investigated with highly directional antennas at $41 \mathrm{GHz}$. The result from the study showed that the angle of the corridor corner can result in power loss.

The study from [90] investigated the use of two types of combinations of antennas that is when Tx and Rx are both horn (horn-horn) antennas and when Tx is horn and the $\mathrm{Rx}$ is omnidirectional (horn-omni) antenna using a channel-sounding with sweptfrequency method. Measurement campaigns were carried out in the corridor for 57 to $64 \mathrm{GHz}$ frequency band. The result showed that limited AOA is observed in MPCs due to the guided nature of propagation in the corridor without much difference in the hornhorn and horn-omni antenna combination. Studies from [105] showed a relative lower values of RMSDS for measurement campaigns at $60 \mathrm{GHz}$ in different corridors. The propagation effects and characteristic for $74 \mathrm{GHz}$ in an entrance hall was reported in [106]. A comparison of mmWave channel measurements for indoor corridors and hallways environment is summarized in Table 3.

\subsection{Indoor Laboratory}

The laboratory environment is composed of workbenches, desks, equipment, tables and enclosed by walls and ceiling made of different materials, and windows. In [93], it was reported that the PLE is identical with free space path loss exponent (FSPLE) based on NB measurements at $28 \mathrm{GHz}$ in indoor laboratory. In [96,97], statistical coefficient of Rician and Nakagami distribution functions for $30 \mathrm{GHz}$ propagation channel using measurement results in a LOS showed that the value of the coefficient varies with the distance between the Tx and Rx, and a good fit was obtained for small scale fading characteristics. The measurement system was designed and developed in [108] for an indoor propagation map at $38 \mathrm{GHz}$ which showed that propagation conditions were largely affected by reflection. A measurement campaign was presented in [100,102] for frequency between 1 and $40 \mathrm{GHz}$ for LOS and NLOS. The RMSDS, PL and K-Factor for various ranges of frequency were presented in [100] while the reverberation time was shown to decrease with frequency in [102]. The diffraction due to blockage from cylindrical blocks with different materials and the human body at $45 \mathrm{GHz}$ was presented in [109]. The signal attenuation by the human body was found to be smaller than the cylindrical block which indicated that the diffraction by the human body was better. 
Multipath parameters for wideband $60 \mathrm{GHz}$ channel were reported in [104]. The RMSDS values of $12 \mathrm{~ns}$ in LOS and $21 \mathrm{~ns}$ in NLOS scenario were observed and the channel also exhibited enhanced frequency selective characteristics. The temporal variation of the $60 \mathrm{GHz}$ channel due to the presence of humans was reported in $[110,111]$. The propagation characteristic for $60 \mathrm{GHz}$ for environment with and without the movement of people in a LOS and NLOS was presented [111]. The number of bodies, speed and the propagation environment resulted in a fluctuation of the received signal between fixed terminals. More studies on the effect of human activity from the number of people between zero and fifteen persons for a $60 \mathrm{GHz}$ channel were reported in [110]. The results showed that direct part shadowing from the human body can result in attenuation of more than $20 \mathrm{dBm}$ for some duration based on the number of people. Table 4 summarizes a comparison of mmWave channel measurements for indoor laboratory environments.

\subsection{Other Indoor Scenarios}

Rising interest to use the mmWave in different application scenarios led to indoor channel measurements in the indoor library, indoor lobby and courtyard, indoor shopping malls, indoor hospital, indoor tunnels, indoor airport terminal building, maintenance hangar, and hall in passenger terminals, and indoor railway station.

A Study in a shopping mall was conducted in [114] using a wideband directional channel measurement. A high correlation was observed in the multipath components of the 28 and $140 \mathrm{GHz}$. Propagation studies in large halls inside the airport from [116,117] reported PLEs in LOS close to that of free space curve $(n=2)$ where the Tx and Rx were positioned at $8 \mathrm{~m}$ and $1.5 \mathrm{~m}$, respectively. Table 5 gives a comparison of mmWave channel measurements for indoor libraries and other indoor environments.

Some measurements were conducted at $\mathrm{W}$-band $(75-110 \mathrm{GHz})$ for a short distance in indoor environments. In $[118,119]$, the measurements were conducted at $\mathrm{W}$-band for a very short distance in an indoor environment to study the reflection from wood, polymer, and metal [119] and the channel variation based on PDP at 5-25 cm Tx-Rx separation distance with $5 \mathrm{~cm}$ step [118]. It was found that the PLE of W-band is almost identical with free space PLE.

\section{Path Loss and RMSDS Results and Discussion}

\subsection{Path Loss Analysis}

Based on all mentioned path loss models in Section 3.1, the path loss mainly depends on the operating frequency, Tx-Rx separation distance, the environment effects (presented in the PLE $(n)$ and shadowing effects $\left(X_{\sigma}\right)$. Table 6 presents the CI and FI path loss model parameters based on different measurements in indoor office environments for LOS and NLOS scenarios among different mmWave frequencies. The CI and FI path loss model parameters for different indoor halls, corridors, libraries, and laboratories are presented in Table 7. Based on the CI path loss model, Table 6 shows that the PLE values for LOS indoor office environments are equal to or less than of FSPLE value of 2 for all studied mmWave frequencies. In some indoor office environments, the PLE $(n)$ is lower (below 1.5) and even below 1 . This implies that there are strong MPCs from different scattering objects and many MPCs are added up constructively. In [37], the PLE values are up to 4.7 for 28 and $73 \mathrm{GHz}$ in the indoor office. These values are abnormal as compared with other studies. The high PLE which is more than FSPLE in LOS indoor environment is due to the cross-polarization between the Tx and Rx antenna. In [37], the results showed that using the same environment with the same measurement setup, the PLE values are 1.1 and 1.3 at 28 and $73 \mathrm{GHz}$, respectively, using V-V polarization. However, for the V-H (cross) polarization, the PLE values are 2.5 and 3.5 at 28 and $73 \mathrm{GHz}$, respectively. This implies that the received power degraded by 14 and $22 \mathrm{~dB} /$ decade using cross polarizations at 28 and $73 \mathrm{GHz}$, respectively. The 3GPP FI path loss model for LOS indoor office environment shows the line slope $\beta$ values are less than the FSPLE value for all listed mmWave frequencies in Table 6. 
The PLE and $\beta$ values are less than the FSPLE value for all frequencies in LOS indoor corridors $[35,36,46,72,76,91-95,98-100]$ as depicted in Table 7 . The PLE values are around FSPLE value in large halls as in $[107,116,117]$. In $[116,117]$, the PLE for LOS at $28 \mathrm{GHz}$ along $300 \mathrm{~m}$ big hall in passengers terminals is 2.2 (more than the FSPLE value of 2 by 0.2 ). In [107], the PLE along $50 \mathrm{~m}$ LOS hallway is 2 at $39 \mathrm{GHz}$. For the library [112] and the laboratory [107] environments, the PLE values are identical with FSPLE value.

Table 6. Path Loss and Delay Spread for different studies in indoor offices.

\begin{tabular}{|c|c|c|c|c|c|}
\hline Source & Freq. (GHz) & Scenarios & $\begin{array}{l}\text { CI Model } \\
n, \sigma(\mathrm{dB})\end{array}$ & $\begin{array}{l}\text { FI Model } \\
\beta, \sigma(\mathrm{dB})\end{array}$ & RMSDS (ns) \\
\hline \multirow{2}{*}{ [37] } & \multirow{2}{*}{28} & LOS & $1.1-4.1,1.8-8.0$ & $0.8-1.4,1.4-2.0$ & $0.7-134.4$ \\
\hline & & NLOS & $2.7-5.1,9.4-11.6$ & $2.3-3.6,9.3-10.6$ & $0.6-198.5$ \\
\hline \multirow{2}{*}{ [43] } & \multirow{2}{*}{28} & LOS & $1.9,2.1$ & $1.7,2.1$ & - \\
\hline & & NLOS & $2.8,6.2$ & $1.5,5.8$ & $<100(18.9)$ \\
\hline \multirow{2}{*}{ [44] } & \multirow{2}{*}{28} & LOS & \multirow{2}{*}{-} & $1.9,2.2$ & $20-50$ \\
\hline & & NLOS & & $3.6,2.9$ & $20-50$ \\
\hline [72] & 28 & NLOS & - & $2.3,3.4$ & - \\
\hline \multirow{2}{*}{ [46] } & \multirow{2}{*}{28} & LOS & 1.6 and $1.8,0.7$ and 0.6 & 1.3 and $1.5,0.9$ and 0.8 & \multirow{2}{*}{-} \\
\hline & & NLOS & 2.1 and $2.5,2$ and 3.5 & 1.2 and $1.4,1.6$ and 3.2 & \\
\hline \multirow{2}{*}{ [47] } & \multirow{2}{*}{28} & LOS & $1.5,1.7$ & $1.4,1.7$ & $5-20$ \\
\hline & & NLOS & $2.2,3.4$ & $2.2,3.3$ & $10-40$ \\
\hline [49] & 28 & LOS & $1.6-1.8,0.7-2.7$ & - & $5-25$ \\
\hline [50] & 28 & LOS & $1.7,1.3$ and 3.1 & - & $10-30$ \\
\hline [75] & 30 & LOS & - & - & $2.5-28$ \\
\hline [52] & 30 & LOS & $2.0,0.1$ & $1.9,0.1$ & - \\
\hline [55] & 32 and 39 & LOS & 1.9 and $1.8,2.5$ and 2.2 & - & 24.3 and 20.5 \\
\hline \multirow{2}{*}{ [54] } & \multirow{2}{*}{38} & LOS & $2.0,4.6$ & $0.9,3.1$ & \multirow{2}{*}{-} \\
\hline & & NLOS & $2.9,6.8$ & $1.3,6.2$ & \\
\hline [120] & 37.2 & LOS & $1.5-2.1,4.4-5.5$ & - & $8-16$ \\
\hline [80] & 60 & LOS & - & $1.3,-$ & - \\
\hline [29] & 60 & LOS & - & $1.3,5.1$ & $5-20$ \\
\hline [83] & 60 & LOS & $1.9,1.7$ & - & \\
\hline \multirow{2}{*}{ [84] } & \multirow{2}{*}{60} & LOS & $0.6-1.2,1.3-2.7$ & - & \multirow{2}{*}{-} \\
\hline & & NLOS & $2.7-5.4,2.7-3.9$ & - & \\
\hline$[58,59]$ & 60 & LOS & $2.1,7.9$ & - & $2-30$ \\
\hline [60] & 60 & NLOS & - & - & $3.3-5.7$ \\
\hline \multirow{2}{*}{ [87] } & \multirow{2}{*}{58} & LOS & $1.2,2.7$ & - & $5-35$ \\
\hline & & NLOS & $5.4,3.9$ & - & $5-45$ \\
\hline [66] & 60 & LOS & - & - & $5-20$ \\
\hline$[69,70]$ & 60 & LOS & $1.6-1.8,0.1-1.1$ & - & - \\
\hline \multirow[t]{2}{*}{ [62] } & \multirow[t]{2}{*}{70} & LOS & $1.7,2.2$ & \multirow[t]{2}{*}{ - } & \multirow[t]{2}{*}{-} \\
\hline & & NLOS & $2.9,6.8$ & & \\
\hline \multirow[t]{2}{*}{ [37] } & \multirow[t]{2}{*}{73} & LOS & $1.3-4.7,2.4-8.6$ & $0.5-1.6,1.4-4.6$ & $0.5-143.8$ \\
\hline & & NLOS & $3.2-6.4,9.7-15.9$ & $1.3-2.7,7.5-11.3$ & $0.5-142$ \\
\hline
\end{tabular}


Table 7. Path Loss and Delay Spread for different studies in hall, corridor, library, and laboratory.

\begin{tabular}{|c|c|c|c|c|c|}
\hline Source & Freq. (GHz) & Scenarios & $\begin{array}{l}\text { CI Model } \\
n, \sigma(\mathrm{dB})\end{array}$ & $\begin{array}{l}\text { FI Model } \\
\beta, \sigma(\mathrm{dB})\end{array}$ & RMSDS (ns) \\
\hline$[35,36,94]$ & 28 & $\begin{array}{l}\text { LOS } \\
\text { NLOS }\end{array}$ & $\begin{array}{l}0.6-1.8,2.1-3.8 \\
3.6,5.7\end{array}$ & $\begin{array}{c}0.9-1.2,2.0-3.1 \\
3.0,5.3\end{array}$ & $\begin{array}{c}1-11.7 \\
1-11\end{array}$ \\
\hline$[116,117]$ & 28 & $\begin{array}{l}\text { LOS } \\
\text { NLOS }\end{array}$ & $\begin{array}{c}2.2,1.2 \text { and } 1.3 \\
3.0 \text { and } 2.7,7.8 \text { and } 5.3\end{array}$ & - & - \\
\hline [72] & 28 & LOS & - & $1.7, / 2.4$ & - \\
\hline$[46]$ & 28 & LOS & 1.3 and $1.5,0.9$ and 0.8 & 1 and $1.3,1.0$ and 1.3 & - \\
\hline [112] & 28 & $\begin{array}{l}\text { LOS } \\
\text { NLOS }\end{array}$ & $\begin{array}{c}2.1,4.2 \\
3.3,13.5\end{array}$ & $\begin{array}{c}1.8,4.1 \\
1.3,13.0\end{array}$ & $\begin{array}{c}27.5-45 \\
25-63\end{array}$ \\
\hline$[91,92]$ & 28 & LOS & - & $1.5,0.5$ & $5-25$ \\
\hline [95] & 28 & $\begin{array}{l}\text { LOS } \\
\text { NLOS }\end{array}$ & $\begin{array}{c}1.9,4.2 \\
-\end{array}$ & - & $\begin{array}{l}<60 \\
<60\end{array}$ \\
\hline [93] & 28 & LOS & $1.7-2.1,0.7-5.5$ & - & - \\
\hline [98] & 31 & $\begin{array}{l}\text { LOS } \\
\text { NLOS }\end{array}$ & $\begin{array}{l}1.7,2.2 \\
2.9,6.8\end{array}$ & - & - \\
\hline$[35,36]$ & 38 & LOS & $0.8-1.3,1.3-3.3$ & $0.9-1.5,2.3-4.3$ & $1-11$ \\
\hline$[76]$ & 40 & LOS & $1.8,4.7$ & $1.8,4.7$ & - \\
\hline [100] & 30 and 40 & LOS & - & $1.4,-$ & $1-8$ \\
\hline [101] & 30 and 39 & $\begin{array}{l}\text { LOS } \\
\text { NLOS }\end{array}$ & - & $\begin{array}{l}1.9 \text { and } 1.8,- \\
2.8 \text { and } 2.4,-\end{array}$ & $\begin{array}{c}2-10 \\
1-8\end{array}$ \\
\hline [107] & 39 & LOS & 2 and $1.5,5.1$ and 4.1 & 2.1 and $1.3,5.1$ and 4.0 & - \\
\hline$[103]$ & 41 & NLOS & $1.6-2.2,2.2-3.0$ & - & $1-10$ \\
\hline [79] & 60 & LOS & $1.9,8.6$ & - & $4.6-47.3$ \\
\hline [111] & 60 & $\begin{array}{l}\text { LOS } \\
\text { NLOS }\end{array}$ & $\begin{array}{l}1.8,1.1 \\
2.0,3.8 \\
\end{array}$ & $\begin{array}{l}- \\
-\end{array}$ & - \\
\hline [104] & 60 & $\begin{array}{l}\text { LOS } \\
\text { NLOS }\end{array}$ & $\begin{array}{l}- \\
-\end{array}$ & $\begin{array}{l}- \\
-\end{array}$ & $\begin{array}{l}12.3-21.1 \\
18.5-31.7\end{array}$ \\
\hline [105] & 60 & LOS & - & - & $5-30$ \\
\hline [99] & 30 and 60 & $\begin{array}{l}\text { LOS } \\
\text { OLOS } \\
\text { NLOS }\end{array}$ & $\begin{array}{l}1.7 \text { and } 1.8,3.7 \text { and } 3.8 \\
1.8 \text { and } 1.9,1.2 \text { and } 1.4 \\
2.3 \text { and } 2.5,5.9 \text { and } 7.2\end{array}$ & $\begin{array}{l}- \\
- \\
-\end{array}$ & $\begin{array}{c}6.7 \text { and } 3.4 \\
27.1 \text { and } 23.5 \\
28.3 \text { and } 22.5\end{array}$ \\
\hline [90] & 60 & LOS & - & - & $<70$ \\
\hline
\end{tabular}

The standard deviation values of the shadowing effect (deviation from log-linear-fit) vary from 0.1 to $5.5 \mathrm{~dB}$ for $\mathrm{CI}$ model and between 0.1 and $5.1 \mathrm{~dB}$ for FI model at all listed LOS studies in Tables 6 and 7. The large standard deviation values of $8,8.6 \mathrm{~dB}$ at 28 and $73 \mathrm{GHz}$, respectively, for CI models [37], are for cross polarizations and $8.6 \mathrm{~dB}$ at $60 \mathrm{GHz}[79]$ is due to the penetration effects for one measurement locations.

The PLE values for NLOS indoor office environments vary from 2.1 to 5.4 for all listed frequencies in Table 6. In [37], the PLE for cross polarization at $73 \mathrm{GHz}$ is 6.4. The $\beta$ of the 3GPP FI path loss model in NLOS indoor office vary from 1.3 to $3.6[37,43,44,46,54]$ for different mmWave frequencies. The PLE values for NLOS indoor corridor environments $[94,98,103,111,116,117]$ vary from 1.6 to 3.6 at different frequencies as shown in Table 7. The PLEs for NLOS scenarios vary from 2 to 3.3 for hall [116,117], library [112], and laboratory [111]. The $\beta$ values for the FI model are 3 and 1.3 at $28 \mathrm{GHz}$ in the indoor corridor [94] and library [112]. It is worth mentioning that the PLE is not frequency-dependent 
in an indoor environment and it depends on the structure of the environment and the type of environment.

It can be noted from the PLE and $\beta$ values of the CI and FI path loss models are similar for LOS scenarios for most of the listed studies in Tables 6 and 7, however, for NLOS scenarios, there is a deviation between both models in most of the indoor environments.

Figure 5 presents the CI and FI path loss models along $100 \mathrm{~m}$ at 28 and $38 \mathrm{GHz}$ for LOS and NLOS scenarios. It can be shown that the PLEs at $28 \mathrm{GHz}$ are 1.9 and 2.8 in indoor offices for LOS and NLOS, respectively, [43]. In the same environment, the slope line values for the FI model are 1.7 and 1.5 for LOS and NLOS, respectively. The CI and FI models for LOS are comparable ( 0.2 difference in PLEs, which is around $2 \mathrm{~dB}$ per decade). The deviation of the FI model comparing with CI based on the reference distance $(1 \mathrm{~m}$ in most cases of the indoor environments) can be explored from the deviation of floating-intercept from free space path loss at the reference distance. In [43], the $\alpha$ value of the FI model is 63.2 which is more than the FSPL value at $d_{0}$ of $1 \mathrm{~m}$ by $1.8 \mathrm{~dB}$. However, for the NLOS scenario, the $\alpha$ value of the FI model is more than the FSPL value at $d_{0}$ of $1 \mathrm{~m}$ by $18.7 \mathrm{~dB}$ from FSPL at a reference distance of $1 \mathrm{~m}$.

In [54], the same findings were explored for $38 \mathrm{GHz}$ in the indoor office environment as shown in Figure 5. It can be seen that for the LOS scenario, the PLE for the CI model and $\beta$ for FI model are 2 and 0.9 , and the $\alpha$ value of the FI model is more than the FSPL value at $d_{0}$ of $1 \mathrm{~m}$ by $14.3 \mathrm{~dB}$. The NLOS line slope of FI model is less than the PLE of the CI model by around $16 \mathrm{~dB}$ per decade. The $\alpha$ value of the FI model is more than the FSPL value at $d_{0}$ of $1 \mathrm{~m}$ by $19.6 \mathrm{~dB}$. Base on all mmWave studies in different LOS and NLOS indoor environments, the FI and CI path loss models can fit the experimental data well in LOS scenarios, however, for NLOS scenarios the CI model is preferred.

The path loss is calculated for LOS and NLOS indoor environments based on the CI model for different mmWave bands; namely $30 \mathrm{GHz}, 40 \mathrm{GHz}$, and $70 \mathrm{GHz}$ as shown in Figures $6-11$. As it is noted from Tables 6 and 7, for all listed studies, the PLE trend is not monotonic with frequency, hence, the same PLE can be applied for different frequencies. For each band, Figures 6-11 show that with the same PLE, the path loss values are comparable for all listed frequencies in the same band, i.e., at $30 \mathrm{GHz}$ band $(28 \mathrm{GHz}, 30 \mathrm{GHz}, 32 \mathrm{GHz}$, and $39 \mathrm{GHz}$ ), using 0.6 PLE the maximum path loss difference between the lowest frequency in the band $28 \mathrm{GHz}$ and the highest one $39 \mathrm{GHz}$ is around $3 \mathrm{~dB}$. The path loss is affected by the construction and the structure of the environments, which can be explored from PLE values. For example, in a narrow corridor and closed indoor office with concrete walls available (acts as a wave-guide for the received signal), the PLE is less than 1 for different frequencies $[35,36,84,94]$.

\subsection{RMSDS Analysis}

The RMSDS values vary from 0.5 to $134.4 \mathrm{~ns}$ and from 0.5 to $198.5 \mathrm{~ns}$ for LOS and NLOS scenarios, respectively, among all listed frequencies in Tables 6 and 7. Based on these studies in different indoor environments, the RMSDS trend is not monotonic with $\mathrm{Tx}-\mathrm{Rx}$ separation distance and frequency. It depends on the structure of the environment and the measurement setup. For the narrow beamwidth of the antenna and the small indoor environment, the RMSDS is small. The delay spread of mmWave frequencies is considerably similar to the currently used frequency bands below $3 \mathrm{GHz}$. Tables 6 and 7 presents the RMSDS for most studies in the literature at mmWave frequencies. 


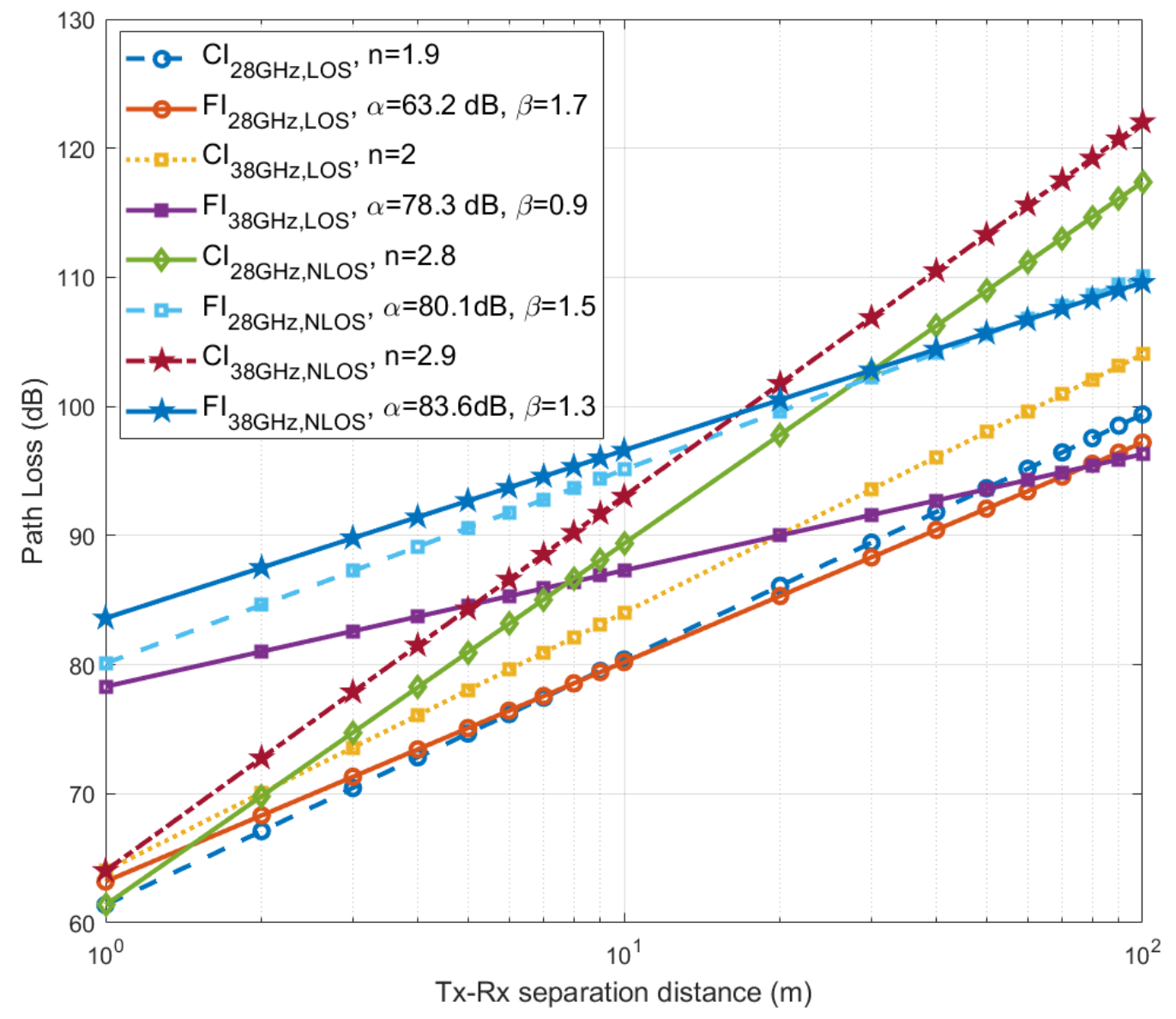

Figure 5. Comparision of CI and FI models at 28 and $38 \mathrm{GHz}$ for LOS and NLOS environments.

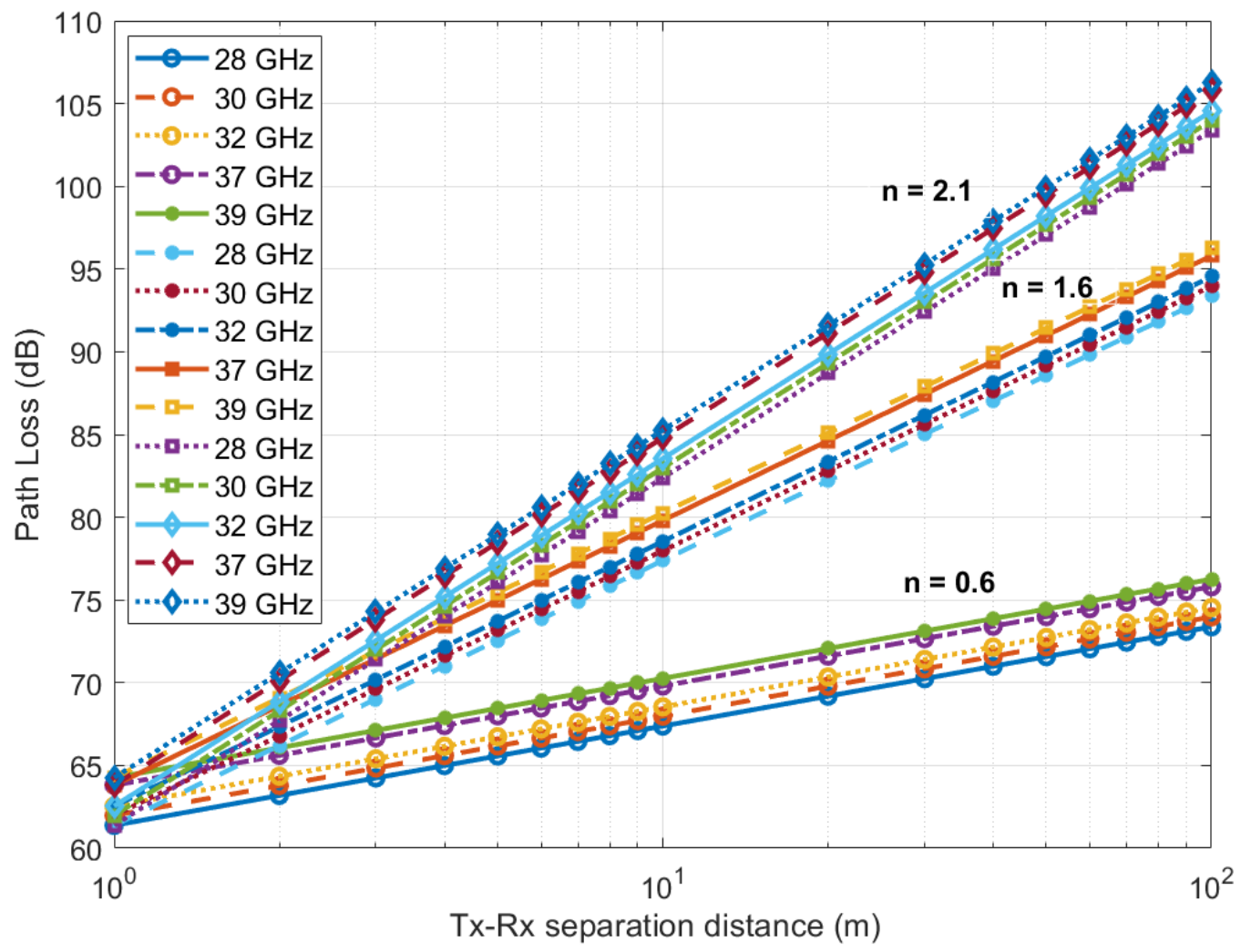

Figure 6. Path Loss at LOS environments for $30 \mathrm{GHz}$ bands. 


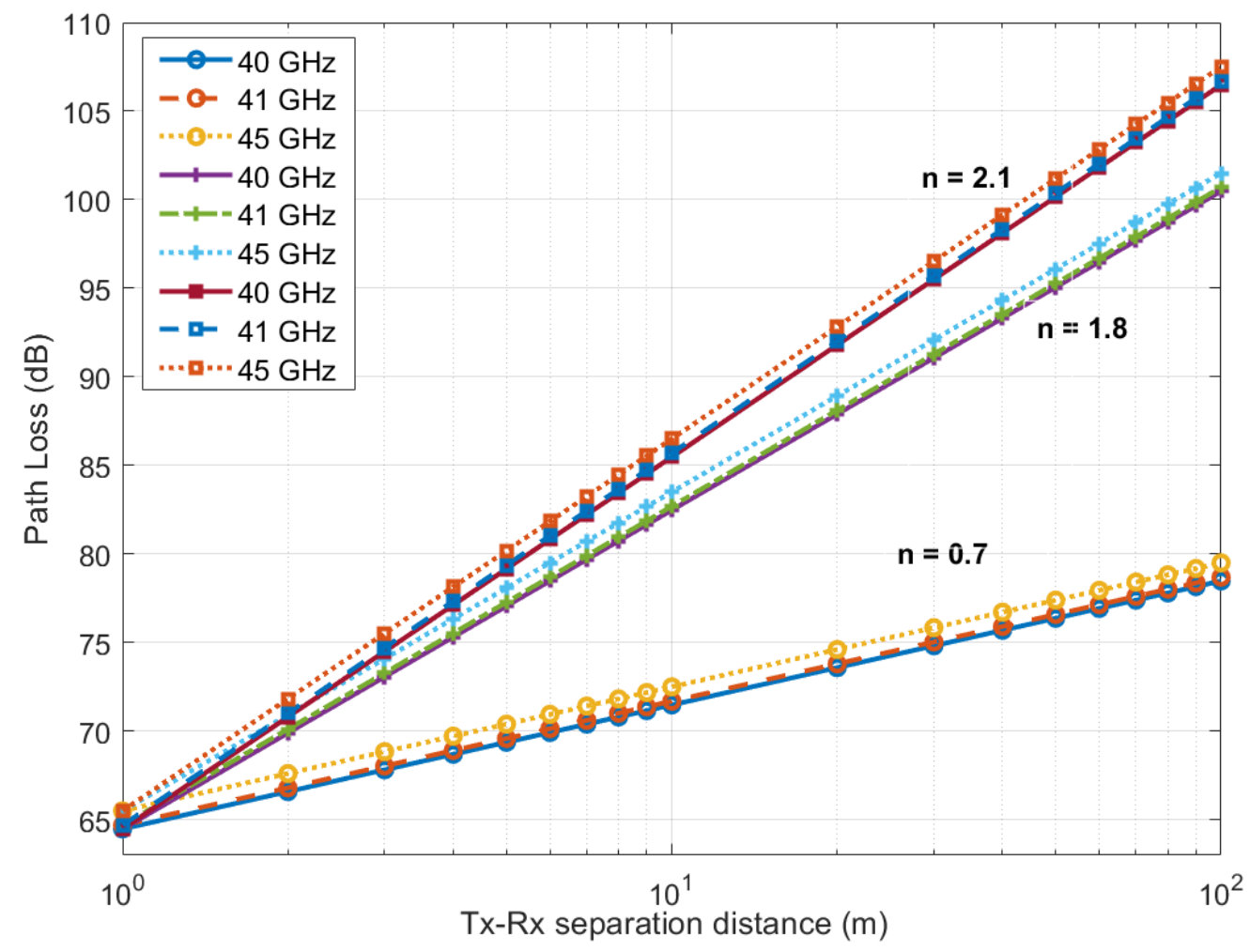

Figure 7. Path Loss at LOS environments for $40 \mathrm{GHz}$ bands.

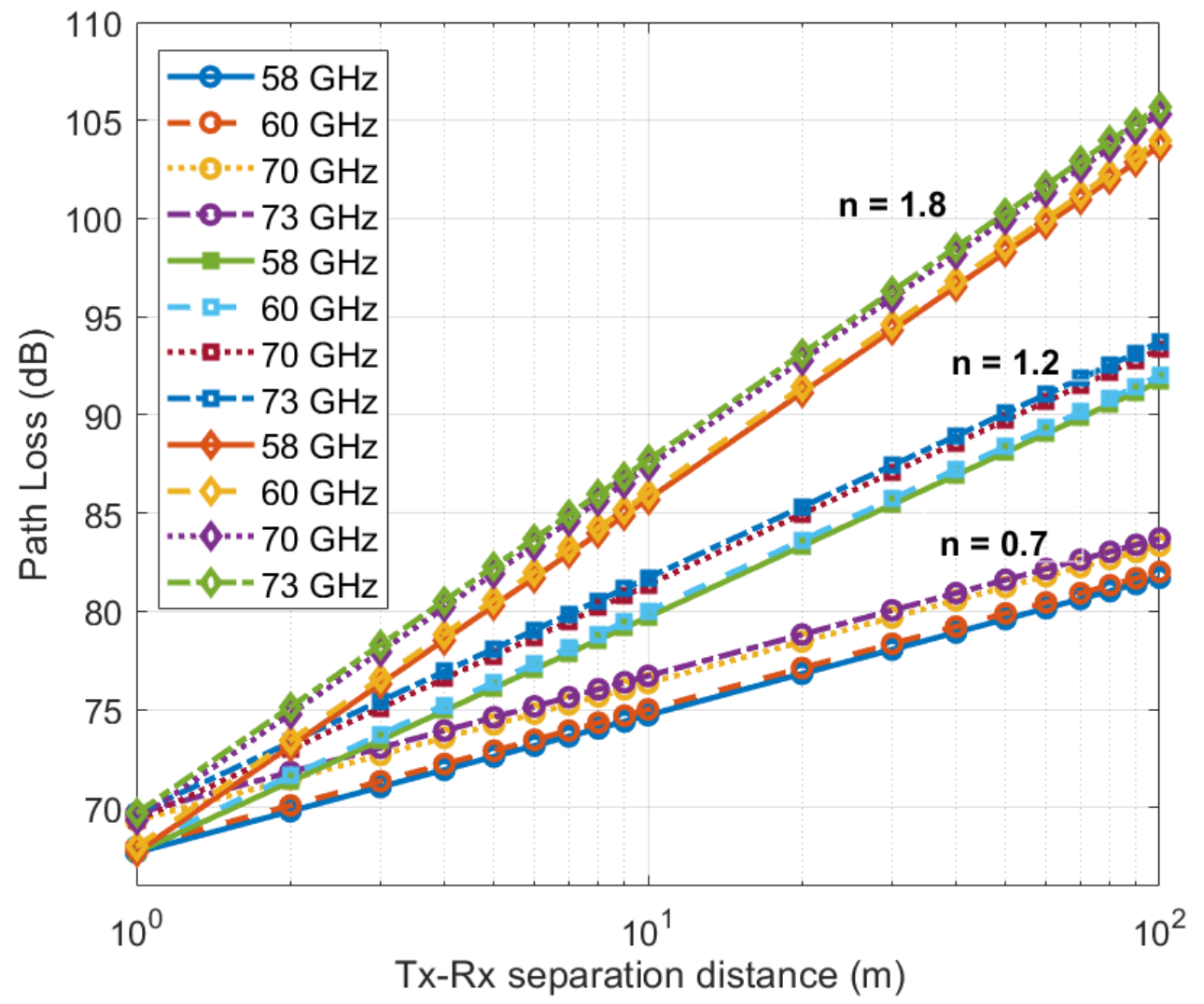

Figure 8. Path Loss at different LOS environments for $70 \mathrm{GHz}$ bands. 


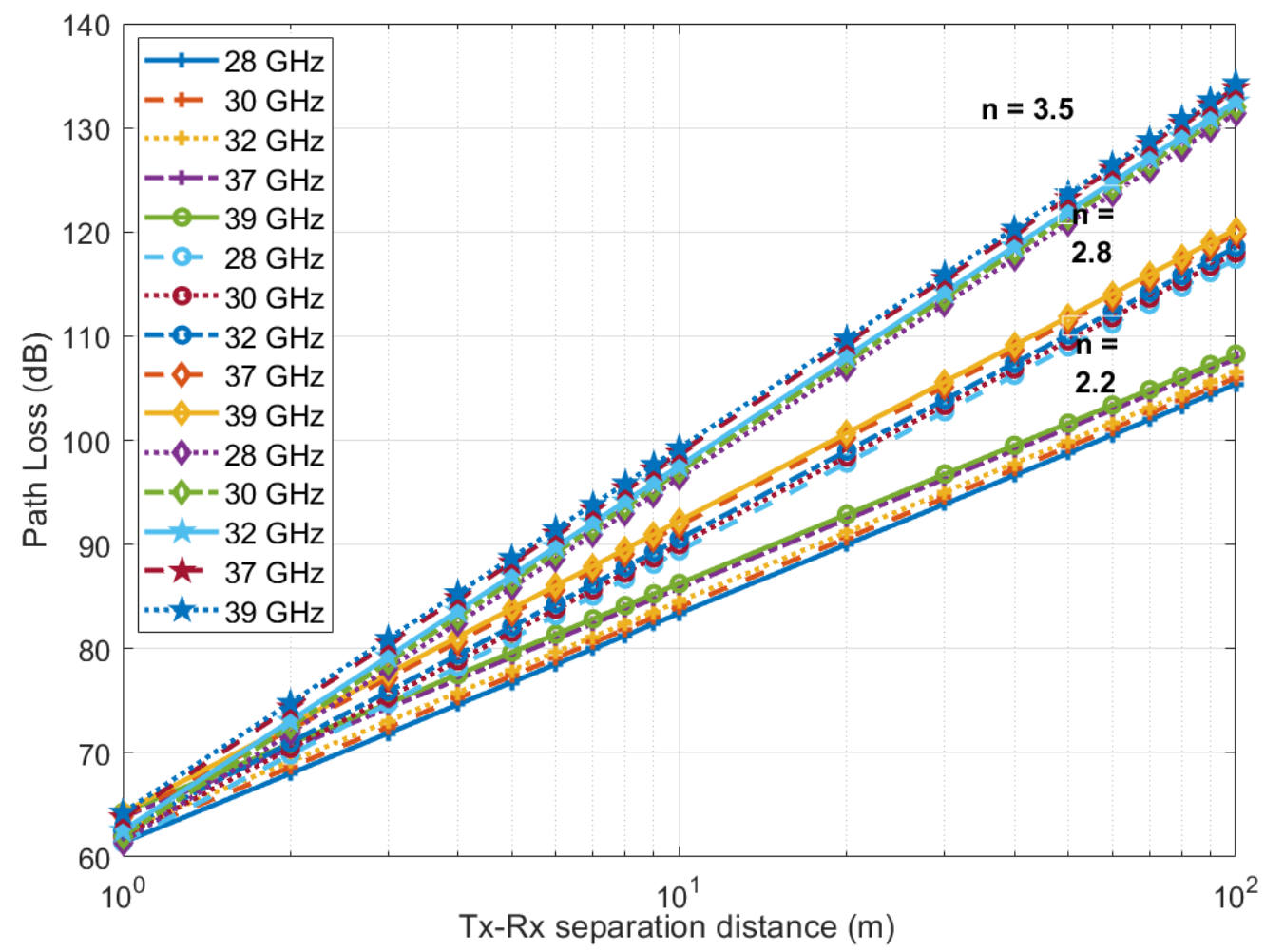

Figure 9. Path Loss at NLOS environments for $30 \mathrm{GHz}$ bands.

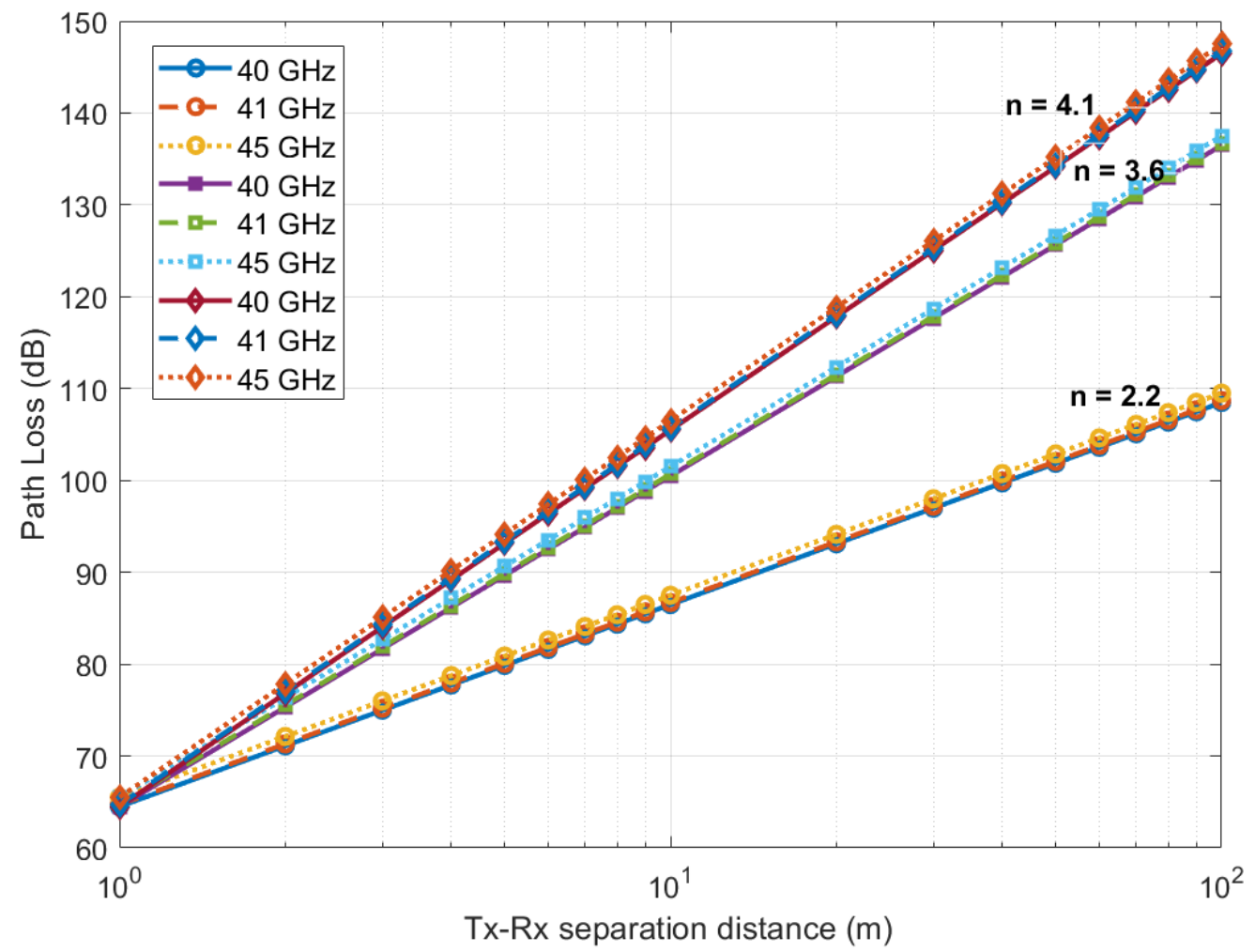

Figure 10. Path Loss at NLOS environments for $40 \mathrm{GHz}$ bands. 


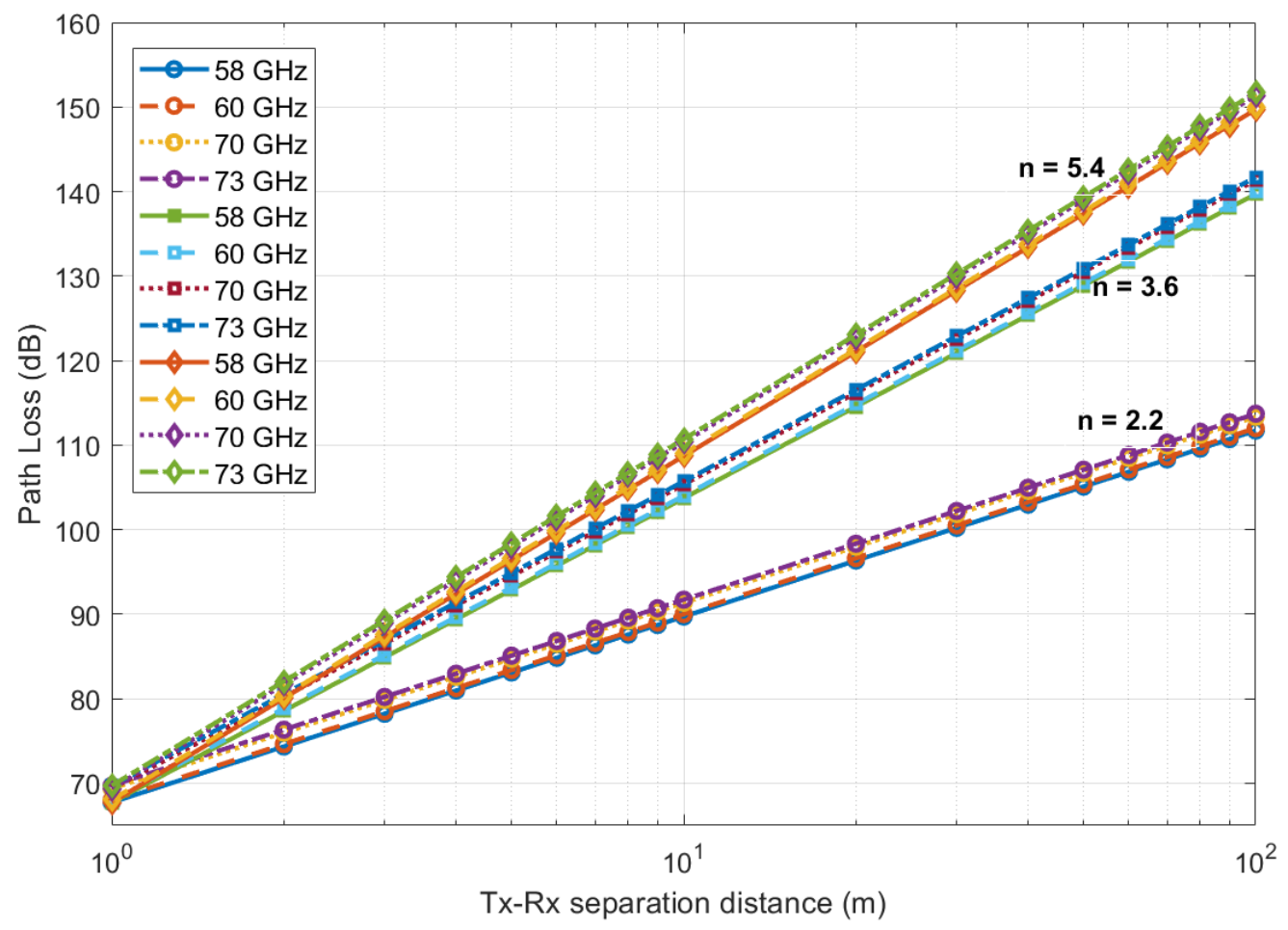

Figure 11. Path Loss at NLOS environments for $70 \mathrm{GHz}$ bands.

\subsection{Summary}

Based on the review of many results of the path loss model of mmWave bands at different frequencies from 28 to $73 \mathrm{GHz}$ in different indoor environments at different regions in the world, the operating frequencies for indoor environments can be grouped into three different bands named $30 \mathrm{GHz}, 40 \mathrm{GHz}$, and $70 \mathrm{GHz}$. The $30 \mathrm{GHz}$ band represents the frequency range from 28 to $39 \mathrm{GHz}$ while the $40 \mathrm{GHz}$ band and $70 \mathrm{GHz}$ bands represent the frequency range of $40-45 \mathrm{GHz}$ and $58-73 \mathrm{GHz}$, respectively. From this study, it can be observed that for the indoor environment with the same physical characteristics the change of the carrier frequency within the same band does not contribute much. For example, using the CI path loss model with PLE of 1.6 and $d_{0}$ of $1 \mathrm{~m}$ the path loss values at such particular Tx-Rx separation distance, i.e., $100 \mathrm{~m}$ for $28 \mathrm{GHz}$ (lowest frequency at $30 \mathrm{GHz}$ band) and $39 \mathrm{GHz}$ (highest frequency at $30 \mathrm{GHz}$ band) are $64.5 \mathrm{~dB}$ and $67.5 \mathrm{~dB}$, respectively. This implies that the path loss value at $39 \mathrm{GHz}$ is only increased by $3 \mathrm{~dB}$ compared to the value of path loss at $28 \mathrm{GHz}$.

From different LOS and NLOS indoor environments studies at mmWave bands, the FI and CI path loss models can fit the experimental data well in the LOS scenario, however, for the NLOS scenario, the CI model is preferred. Based on these studies in different indoor environments, the RMSDS trend is not monotonic with Tx-Rx separation distance and frequency. It depends on the physical structure of the environments and the measurement setup.

\section{Future Trends}

From the survey of the existing works, we discuss the future trends based on the following areas.

\subsection{Critical Indoor Environment}

The 5G wireless networks will be used for different indoor applications such as emergency cases. A common part of any building structure is the stairs, essentially used in emergency cases for fire escape or in natural disasters. Few propagation measurements have been conducted at mmWave for indoor channels in the stairwell [121-123]. In [121,122], the 
path loss was investigated using CI, FI, ABG, and CIF models based on NB measurements at $28 \mathrm{GHz}, 32 \mathrm{GHz}$, and $38 \mathrm{GHz}$ that conducted in two different stairwells in a tropical region, i.e., Malaysia. The path loss models in the stairwell environments indicated that the received power decay is high where the PLE is more than 7. More studies are needed to investigate the radio propagation channel at mmWave in stairwell environments.

Furthermore, propagation measurement at mmWave band in indoor industrial environments is expected to attract more research interest [124]. For instance, the mmWave channel properties were investigated at 28 and $60 \mathrm{GHz}$ based on wideband measurements using VNA in two different factories, which represent light and heavy industry [125]. The wireless channels need more characterization in different indoor industrial environments.

\subsection{Artificial Intelligence}

The use of artificial intelligence (AI) methods such as machine learning and deep learning are now been applied in the field of wireless communication. Recent studies have investigated the use of machine learning for the prediction of path loss models [126-129]. The result of these studies has shown a positive reduction in complexity, amount of time required in measurement and an enhancement in path loss models. Further research is expected in the application of machine learning for the prediction of channel models for indoor environments. Moreover, deep learning is also used to model the path loss for 5G communications with static objects [130]. The influence of moving objects such as vehicles and the heights of Tx and Rx antennas are still an open issue which can be addressed for path loss modelling using deep learning.

\subsection{Channel Characterization for Indoor Devices}

The use of mmWave for dense indoor devices is expected to solve the problem of bandwidth scarcity needed for high data rates. In addition, the mmWave can provide narrow beam communication for device-to-device communication in indoor environments. Examples of devices that benefit from the application of mmWave are wearable devices as presented in [131,132]. The need for characterization of propagation studies for different devices operating at mmWave for indoor environments is expected to attract further research interest.

\subsection{Reconfigurable Intelligent Surface}

The use of reconfigurable intelligent surfaces (RIS) is considered a promising network architecture for 5G, 6G and beyond. The RIS makes use of a surface composed of $N$ elements that are reconfigurable to collect wireless signals from a Tx and passively beamform them towards the desired $\operatorname{Rx}[133,134]$. This is expected to help improve the propagation in indoor environments and overcome the limitations of signal loss attributed to mmWave propagation. Hence, more investigation of path loss models is needed in mmWave for RIS as presented in the recent studies [135-137]. In addition, it is found that most researchers used simplified models for the wireless channel (i.e., i.i.d Rayleigh fading channel). The channel fading is applicable for inexpensive antenna whose inter-distance is larger than half of the wavelength, but their application to metasurface-based RISs made with more fading factors such as small-scale-fading necessitates further investigation $[137,138]$. In addition, the uses of models that accounts of spatially-stationary scattering channel such as the planewave model (isotropic) and plane-wave model (non-isotropic) for metasurface/antenna arrays proposed in $[139,140]$ needs to be explored for mmWave indoor environment.

\subsection{MmWave for $6 \mathrm{G}$}

The current candidate $5 \mathrm{G}$ frequency band ( 24 to $86 \mathrm{GHz}$ ) may not be sufficient due to the fast emerging wireless data traffic and emerging applications. Hence, the 6G wireless system is focused on exploring above $100 \mathrm{GHz}$ to overcome spectrum scarcity and bandwidth limitation [141]. Furthermore, more communication is envisaged to be done indoors since $80 \%$ of the time people stay in indoors [142]. Hence, more research work is expected 
in the study of mmWave frequencies from 100 to $300 \mathrm{GHz}$ and beyond (sub-THz and $\mathrm{THz}$ wireless networks) in indoor environments [143]. This is expected to open several research issues on propagation models at various indoor locations, and penetration measurement for different materials. The performance of the current $5 \mathrm{G} \mathrm{mmWave} \mathrm{frequency} \mathrm{bands} \mathrm{can} \mathrm{be}$ compared with $6 \mathrm{G}$ proposed frequency bands. Furthermore, the $6 \mathrm{G}$ channel measurement is time consuming, and the design of a high-performance channel sounder that can fulfill the requirement of $6 \mathrm{G}$ channel is still open research [144].

\subsection{Near-Ground Propagation Measurements}

The propagation measurement of mmWave near-groud is still a challenging and interesting research area. The mmWave band will be used in V2V communication in which two antennas in the front and rear bumper of vehicles are installed. In such cases, the Tx and $\mathrm{Rx}$ antennas are located close to the ground $[145,146]$. Furthermore, The internet of things (IoT) and sensors application operating on mmWave and propagate near the ground will open a new direction for future research [147].

\section{Conclusions}

A review of indoor mmWave channel measurements at different candidate frequencies for $5 \mathrm{G}$ wireless networks has been presented. The indoor channel characteristics of the mmWave band from two main wireless channel perspectives, that is, the path loss and time dispersion have been discussed. While the path loss increases as the operating frequency increases, the path loss exponent is not frequency-dependent, but it depends on the environment type and structure. The best models for path loss in the indoor environment at the mmWave bands such as the CI and FI models for LOS channels and CI model for NLOS channels were identified. It was noted that the mmWave indoor channel has a small RMSDS value for narrow HBPW and a small size indoor environment. The future trends for the mmWave indoor environment have been discussed in this paper. Further research works are needed in the study of mmWave industrial indoor environments, indoor stairwell environment, propagation studies for wearable devices, reconfigurable intelligent surfaces, and application of artificial intelligence. This survey has provided a comprehensive review of the work that has been conducted on measurement campaigns and propagation models for the indoor mmWave environment. The engineering and research community will find it helpful in the design of an optimum indoor wireless network, and the performance of mmWave for 5G, 6G wireless networks and beyond.

Author Contributions: Conceptualization, A.A.-S.; Data curation, A.A.-S.; Formal analysis, A.A.-S., M.C. and O.E.; Funding acquisition, A.A.-S. and M.C.; Investigation, A.A.-S., M.C. and O.E.; Methodology, A.A.-S., M.C. and O.E.; Project administration, A.A.-S. and M.C.; Resources, A.A.-S. and O.E.; Software, A.A.-S. and O.E.; Supervision, A.A.-S., M.C. and S.K.A.R.; Validation, A.A.-S., M.C., O.E. and S.K.A.R.; Visualization, A.A.-S., M.C. and O.E.; writing-original draft preparation, A.A.-S., M.C. and O.E.; Writing—review and editing, A.A.-S., M.C., O.E., S.K.A.R., Y.A.A.-G. and T.A.-H. All authors have read and agreed to the published version of the manuscript.

Funding: This work was supported by Manu Lab, NTNU, Gjøvik.

Data Availability Statement: The data presented in this study are available on request from the corresponding author.

Conflicts of Interest: The authors declare no conflict of interest. 


\section{References}

1. RESOLUTION 238 (WRC-15). Studies on Frequency Related Matters for International Mobile Telecommunications Identification Including Possible Additional Allocations to the Mobile Services on a Primary Basis in Portion(s) of the Frequency Range between 24.25 and 86 GHz for the Future Development of International Mobile Telecommunications for 2020 and Beyond; International Telecommunications Union (ITU): Geneva, Switzerland, 2015; pp. 424-426.

2. Almers, P.; Bonek, E.; Burr, A.; Czink, N.; Debbah, M.; Degli-Esposti, V.; Hofstetter, H.; Kyösti, P.; Laurenson, D.; Matz, G.; et al. Survey of channel and radio propagation models for wireless MIMO systems. EURASIP J. Wirel. Commun. Netw. 2007, 2007, 1-19. [CrossRef]

3. Shiu, D.S.; Foschini, G.J.; Gans, M.J.; Kahn, J.M. Fading correlation and its effect on the capacity of multielement antenna systems. IEEE Trans. Commun. 2000, 48, 502-513. [CrossRef]

4. Chuah, C.N.; Kahn, J.M.; Tse, D. Capacity of Multi-Antenna Array Systems in Indoor Wireless Environment. In Proceedings of the IEEE GLOBECOM 1998 (Cat. NO. 98CH36250), Sydney, Australia, 8-12 November 1998; Volume 4, pp. $1894-1899$.

5. Weichselberger, W.; Herdin, M.; Ozcelik, H.; Bonek, E. A stochastic MIMO channel model with joint correlation of both link ends. IEEE Trans. Wirel. Commun. 2006, 5, 90-100. [CrossRef]

6. Burr, A.G. Capacity bounds and estimates for the finite scatterers MIMO wireless channel. IEEE J. Sel. Areas Commun. 2003, 21, 812-818. [CrossRef]

7. Debbah, M.; Muller, R.R. MIMO channel modeling and the principle of maximum entropy. IEEE Trans. Inf. Theory 2005, 51, 1667-1690. [CrossRef]

8. Sayeed, A.M. Deconstructing multiantenna fading channels. IEEE Trans. Signal Process. 2002, 50, 2563-2579. [CrossRef]

9. Maxwell, J.C. VIII. A dynamical theory of the electromagnetic field. Philos. Trans. R. Soc. Lond. 1865, 155, 459-512.

10. Harrington, R.F. Field Computation by Moment Methods; Wiley-IEEE Press: Hoboken, NJ, USA, 1968.

11. Yee, K. Numerical solution of initial boundary value problems involving Maxwell's equations in isotropic media. IEEE Trans. Antennas Propag. 1966, 14, 302-307.

12. Kim, S.C.; Guarino, B.; Willis, T.; Erceg, V.; Fortune, S.J.; Valenzuela, R.A.; Thomas, L.W.; Ling, J.; Moore, J.D. Radio propagation measurements and prediction using three-dimensional ray tracing in urban environments at $908 \mathrm{MHz}$ and $1.9 \mathrm{GHz}$. IEEE Trans. Veh. Technol. 1999, 48, 931-946.

13. Saleh, A.A.; Valenzuela, R. A statistical model for indoor multipath propagation. IEEE J. Sel. Areas Commun. 1987, 5, 128-137. [CrossRef]

14. Correia, L.M. Mobile Broadband Multimedia Networks: Techniques, Models and Tools for 4G; Elsevier: Amsterdam, The Netherlands, 2010.

15. Hemadeh, I.A.; Satyanarayana, K.; El-Hajjar, M.; Hanzo, L. Millimeter-wave communications: Physical channel models, design considerations, antenna constructions, and link-budget. IEEE Commun. Surveys Tutor. 2017, 20, 870-913. [CrossRef]

16. Samimi, M.K.; Rappaport, T.S. 3-D millimeter-wave statistical channel model for $5 \mathrm{G}$ wireless system design. IEEE Trans. Microw. Theory Tech. 2016, 64, 2207-2225. [CrossRef]

17. Guerra, A.; Guidi, F.; Dardari, D.; Clemente, A.; D'Errico, R. A millimeter-wave indoor backscattering channel model for environment mapping. IEEE Trans. Antennas Propag. 2017, 65, 4935-4940. [CrossRef]

18. Lim, Y.G.; Cho, Y.J.; Sim, M.S.; Kim, Y.; Chae, C.B.; Valenzuela, R.A. Map-based millimeter-wave channel models: An overview, data for B5G evaluation and machine learning. IEEE Wirel. Commun. 2020, 27, 54-62. [CrossRef]

19. Va, V.; Shimizu, T.; Bansal, G.; Heath, R.W., Jr. Millimeter wave vehicular communications: A survey. Found. Trends Netw. 2016, 10, 1-118. [CrossRef]

20. Niu, Y.; Li, Y.; Jin, D.; Su, L.; Vasilakos, A.V. A survey of millimeter wave communications (mmWave) for 5G: Opportunities and challenges. Wirel. Netw. 2015, 21, 2657-2676. [CrossRef]

21. Giordani, M.; Mezzavilla, M.; Zorzi, M. Initial access in 5G mmWave cellular networks. IEEE Commun. Mag. 2016, 54, 40-47. [CrossRef]

22. Xiao, M.; Mumtaz, S.; Huang, Y.; Dai, L.; Li, Y.; Matthaiou, M.; Karagiannidis, G.K.; Björnson, E.; Yang, K.; Chih-Lin, I.; et al. Millimeter wave communications for future mobile networks. IEEE J. Sel. Areas Commun. 2017, 35, 1909-1935. [CrossRef]

23. Uwaechia, A.N.; Mahyuddin, N.M. A Comprehensive Survey on Millimeter Wave Communications for Fifth-Generation Wireless Networks: Feasibility and Challenges. IEEE Access 2020, 8, 62367-62414. [CrossRef]

24. Huang, J.; Liu, Y.; Wang, C.X.; Sun, J.; Xiao, H. 5G millimeter wave channel sounders, measurements, and models: Recent developments and future challenges. IEEE Commun. Mag. 2018, 57, 138-145. [CrossRef]

25. Busari, S.A.; Huq, K.M.S.; Mumtaz, S.; Dai, L.; Rodriguez, J. Millimeter-wave massive MIMO communication for future wireless systems: A survey. IEEE Commun. Surv. Tutor. 2017, 20, 836-869. [CrossRef]

26. Al-Falahy, N.; Alani, O.Y. Millimetre wave frequency band as a candidate spectrum for 5G network architecture: A survey. Phys. Commun. 2019, 32, 120-144. [CrossRef]

27. Wang, X.; Kong, L.; Kong, F.; Qiu, F.; Xia, M.; Arnon, S.; Chen, G. Millimeter Wave Communication: A Comprehensive Survey. IEEE Commun. Surv. Tutor. 2018, 20, 1616-1653. [CrossRef]

28. Feng, L.; Yang, H.; Hu, R.Q.; Wang, J. MmWave and VLC-based indoor channel models in 5G wireless networks. IEEE Wirel. Commun. 2018, 25, 70-77. [CrossRef]

29. Zwick, T.; Beukema, T.J.; Nam, H. Wideband channel sounder with measurements and model for the $60 \mathrm{GHz}$ indoor radio channel. IEEE Trans. Veh. Technol. 2005, 54, 1266-1277. [CrossRef] 
30. Molisch, A.F.; Foerster, J.R.; Pendergrass, M. Channel models for ultrawideband personal area networks. IEEE Wirel. Commun. 2003, 10, 14-21. [CrossRef]

31. Muqaibel, A.; Safaai-Jazi, A.; Attiya, A.; Woerner, B.; Riad, S. Path-loss and time dispersion parameters for indoor UWB propagation. IEEE Trans. Wirel. Commun. 2006, 5, 550-559. [CrossRef]

32. Mucchi, L.; Marcocci, P. A new parameter for UWB indoor channel profile identification. IEEE Trans. Wirel. Commun. 2009, 8, 1597-1602. [CrossRef]

33. Pirkl, R.J.; Durgin, G.D. Optimal sliding correlator channel sounder design. IEEE Trans. Wirel. Commun. 2008, 7, 3488-3497. [CrossRef]

34. Kivinen, J.; Zhao, X.; Vainikainen, P. Empirical characterization of wideband indoor radio channel at 5.3 GHz. IEEE Trans. Antennas Propag. 2001, 49, 1192-1203. [CrossRef]

35. Al-Samman, A.; Rahman, T.; Azmi, M.; Hindia, M.; Khan, I.; Hanafi, E. Statistical modelling and characterization of experimental mm-wave indoor channels for future 5G wireless communication networks. PLoS ONE 2016, 11, e0163034. [CrossRef] [PubMed]

36. Al-Samman, A.M.; Abd Rahman, T.; Azmi, M.H. Indoor corridor wideband radio propagation measurements and channel models for 5G millimeter wave wireless communications at $19 \mathrm{GHz}, 28 \mathrm{GHz}$, and $38 \mathrm{GHz}$ bands. Wirel. Commun. Mobile Comput. 2018, 2018, 6369517. [CrossRef]

37. Maccartney, G.R.; Rappaport, T.S.; Sun, S.; Deng, S. Indoor office wideband millimeter-wave propagation measurements and channel models at 28 and $73 \mathrm{GHz}$ for ultra-dense 5G wireless networks. IEEE Access 2015, 3, 2388-2424. [CrossRef]

38. Haneda, K.; Tian, L.; Asplund, H.; Li, J.; Wang, Y.; Steer, D.; Li, C.; Balercia, T.; Lee, S.; Kim, Y.; et al. Indoor 5G 3GPP-like channel models for office and shopping mall environments. In Proceedings of the 2016 IEEE International Conference on Communications Workshops (ICC), Kuala Lumpur, Malaysia, 26-27 May 2016; pp. 694-699.

39. Hashemi, H.; Tholl, D. Statistical modeling and simulation of the RMS delay spread of indoor radio propagation channels. IEEE Trans. Veh. Technol. 1994, 43, 110-120. [CrossRef]

40. Rappaport, T.S. Wireless Communications Principles and Practice; Prentice Hall: Upper Saddle River, NJ, USA, 2002.

41. Rappaport, T.S.; Heath, R.W., Jr.; Daniels, R.C.; Murdock, J.N. In Millimeter Wave Wireless Communications; Prentice-Hall: Englewood Cliffs, NJ, USA, 2014.

42. Yin, X.; Ling, C.; Kim, M.D. Experimental multipath-cluster characteristics of 28-GHz propagation channel. IEEE Access 2015, 3, 3138-3150. [CrossRef]

43. Ko, J.; Cho, Y.J.; Hur, S.; Kim, T.; Park, J.; Molisch, A.F.; Haneda, K.; Peter, M.; Park, D.J.; Cho, D.H. Millimeter-wave channel measurements and analysis for statistical spatial channel model in in-building and urban environments at $28 \mathrm{GHz}$. IEEE Trans. Wirel. Commun. 2017, 16, 5853-5868. [CrossRef]

44. Huang, F.; Tian, L.; Zheng, Y.; Zhang, J. Propagation characteristics of indoor radio channel from $3.5 \mathrm{GHz}$ to $28 \mathrm{GHz}$. In Proceedings of the 2016 IEEE 84th Vehicular Technology Conference (VTC-Fall), Montréal, QC, Canada, 18-21 September 2016; pp. 1-5.

45. Li, S.; Liu, Y.; Lin, L.; Wang, M.; Sheng, Z.; Sun, D. Millimeter-wave propagation measurement and simulation in a indoor office environment at $28 \mathrm{GHz}$. In Proceedings of the 2017 Sixth Asia-Pacific Conference on Antennas and Propagation (APCAP), Xi'an, China, 16-19 October 2017; pp. 1-3.

46. Zhou, L.; Xiao, L.; Yang, Z.; Li, J.; Lian, J.; Zhou, S. Path loss model based on cluster at 28 GHz in the indoor and outdoor environments. Sci. China Inf. Sci. 2017, 60, 080302. [CrossRef]

47. Tang, P.; Zhang, J.; Shafi, M.; Dmochowski, P.A.; Smith, P.J. Millimeter wave channel measurements and modelling in an indoor hotspot scenario at $28 \mathrm{GHz}$. In Proceedings of the 2018 IEEE 88th Vehicular Technology Conference (VTC-Fall), Chicago, IL USA, 27-30 August 2018; pp. 1-5.

48. Golmoharnadi, M.; Chowdhury, S.; Jamison, J.; Kravitz, E.; Frolik, J. 28 GHz channel measurements in high multipath, indoor environments. In Proceedings of the 2018 IEEE International Symposium on Antennas and Propagation \& USNC/URSI National Radio Science Meeting, Boston, MA, USA, 8-13 July 2018; pp. 767-768.

49. Li, S.; Liu, Y.; Chen, Z.; Sun, X.; Lin, L. Measurements and modelling of millimeter-wave channel at $28 \mathrm{GHz}$ in the indoor complex environment for $5 \mathrm{G}$ radio systems. In Proceedings of the 2017 9th International Conference on Wireless Communications and Signal Processing (WCSP), Nanjing, China, 11-13 October 2017; pp. 1-6.

50. Ko, J.; Lee, S.U.; Kim, Y.S.; Park, D.J. Measurements and analyses of $28 \mathrm{GHz}$ indoor channel propagation based on a synchronized channel sounder using directional antennas. J. Electromag. Waves Appl. 2016, 30, 2039-2054. [CrossRef]

51. Karstensen, A.; Fan, W.; Carton, I.; Pedersen, G.F. Comparison of ray tracing simulations and channel measurements at mmWave bands for indoor scenarios. In Proceedings of the 2016 10th European Conference on Antennas and Propagation (EuCAP), Davos, Switzerland, 10-15 April 2016; pp. 1-5.

52. Cheng, C.L.; Kim, S.; Zajić, A. Comparison of path loss models for indoor $30 \mathrm{GHz}, 140 \mathrm{GHz}$, and $300 \mathrm{GHz}$ channels. In Proceedings of the 2017 11th European Conference on Antennas and Propagation (EUCAP), Paris, France, 19-24 March 2017; pp. 716-720.

53. Guo, B.; Wu, Y.; Jiao, J.; Lv, B.; Zhou, F.; Ma, Z.; Sun, J.-1. Building entry loss model for 24 to $31 \mathrm{GHz}$ band. In Proceedings of the 2016 International Symposium on Antennas and Propagation (ISAP), Okinawa, Japan, 24-28 October 2016; pp. 60-61. 
54. Kim, M.D.; Liang, J.; Lee, J.; Park, J.; Park, B. Path loss measurements and modeling for indoor office scenario at 28 and 38 GHz. In Proceedings of the 2016 International Symposium on Antennas and Propagation (ISAP), Okinawa, Japan, 24-28 October 2016; pp. 64-65.

55. Khalily, M.; Taheri, S.; Payami, S.; Ghoraishi, M.; Tafazolli, R. Indoor wideband directional millimeter wave channel measurements and analysis at $26 \mathrm{GHz}, 32 \mathrm{GHz}$, and $39 \mathrm{GHz}$. Trans. Emerg. Telecommun. Technol. 2018, 29, e3311. [CrossRef]

56. Sasaki, M.; Inomata, M.; Yamada, W.; Kita, N.; Onizawa, T.; Nakatsugawa, M.; Kitao, K.; Imai, T. Path loss characteristics between different floors from 0.8 to $37 \mathrm{GHz}$ in indoor office environments. In Proceedings of the 2016 International Symposium on Antennas and Propagation (ISAP), Okinawa, Japan, 24-28 October 2016; pp. 66-67.

57. Zhu, J.; Wang, H.; Hong, W. Large-scale fading characteristics of indoor channel at 45-GHz band. IEEE Antennas Wirel. Propag. Lett. 2014, 14, 735-738. [CrossRef]

58. Anderson, C.R.; Rappaport, T.S. In-building wideband partition loss measurements at 2.5 and 60 GHz. IEEE Trans. Wirel. Commun. 2004, 3, 922-928. [CrossRef]

59. Anderson, C.R.; Rappaport, T.S.; Bae, K.; Verstak, A.; Ramakrishnan, N.; Tranter, W.H.; Shaffer, C.A.; Watson, L.T. In-building wideband multipath characteristics at 2.5 and $60 \mathrm{GHz}$. In Proceedings of the IEEE 56th Vehicular Technology Conference, Vancouver, BC, Canada, 24-28 September 2002; Volume 1, pp. 97-101.

60. Dupleich, D.; Fuschini, F.; Mueller, R.; Vitucci, E.; Schneider, C.; Degli Esposti, V.; Thomä, R. Directional characterization of the 60 GHz indoor-office channel. In Proceedings of the 2014 XXXIth URSI General Assembly and Scientific Symposium (URSI GASS), Beijing, China, 16-26 August 2014; pp. 1-4.

61. Dupleich, D.; Häfner, S.; Schneider, C.; Müller, R.; Thomä, R.; Luo, J.; Iqbal, N.; Schulz, E.; Lu, X.; Wang, G. Double-directional and dual-polarimetric indoor measurements at 70 GHz. In Proceedings of the 2015 IEEE 26th Annual International Symposium on Personal, Indoor, and Mobile Radio Communications (PIMRC), Hong Kong, China, 30 August-2 September 2015; pp. 2234-2238.

62. Ohkubo, F.; Akeyama, A.; Hamaguchi, K.; Ogawa, H. Indoor propagation loss in $70 \mathrm{GHz}$ band. In Proceedings of the 2005 IEEE International Symposium on Microwave, Antenna, Propagation and EMC Technologies for Wireless Communications, Beijing, China, 8-12 August 2015; Volume 1, pp. 245-248.

63. Nie, S.; MacCartney, G.R.; Sun, S.; Rappaport, T.S. $72 \mathrm{GHz}$ millimeter wave indoor measurements for wireless and backhaul communications. In Proceedings of the 2013 IEEE 24th Annual International Symposium on Personal, Indoor, and Mobile Radio Communications (PIMRC), London, UK, 8-11 September 2013; pp. 2429-2433.

64. Ryan, J.; MacCartney, G.R.; Rappaport, T.S. Indoor office wideband penetration loss measurements at 73 GHz. In Proceedings of the 2017 IEEE International Conference on Communications Workshops (ICC Workshops), Paris, France, 21-23 May 2017; pp. 228-233.

65. Haneda, K.; Järveläinen, J.; Karttunen, A.; Kyrö, M.; Putkonen, J. Indoor short-range radio propagation measurements at 60 and $70 \mathrm{GHz}$. In Proceedings of the 8th European Conference on Antennas and Propagation (EuCAP 2014), Hague, The Netherlands, 6-11 April 2014; pp. 634-638.

66. Haneda, K.; Järveläinen, J.; Karttunen, A.; Kyrö, M.; Putkonen, J. A statistical spatio-temporal radio channel model for large indoor environments at 60 and $70 \mathrm{GHz}$. IEEE Trans. Antennas Propag. 2015, 63, 2694-2704. [CrossRef]

67. Wu, X.; Wang, C.X.; Sun, J.; Huang, J.; Feng, R.; Yang, Y.; Ge, X. 60-GHz millimeter-wave channel measurements and modeling for indoor office environments. IEEE Trans. Antennas Propag. 2017, 65, 1912-1924. [CrossRef]

68. Liu, P.; Blumenstein, J.; Perović, N.S.; Di Renzo, M.; Springer, A. Performance of generalized spatial modulation MIMO over measured 60GHz indoor channels. IEEE Trans. Commun. 2017, 66, 133-148. [CrossRef]

69. El Hajj, M.; Zaharia, G.; El Zein, G.; Farhat, H.; Sadek, S. Millimeter-wave propagation measurements at 60 GHz in indoor environments. In Proceedings of the 2019 International Symposium on Signals, Circuits and Systems (ISSCS), Iaşi, Romania, 11-12 July 2019; pp. 1-4.

70. El Hajj, M.; El Zein, G.; Zaharia, G.; Farhat, H.; Sadek, S. Angular Measurements and Analysis of the Indoor Propagation Channel at $60 \mathrm{GHz}$. In Proceedings of the 2019 International Conference on Wireless and Mobile Computing, Networking and Communications (WiMob), Barcelona, Spain, 21-23 October 2019; pp. 121-126.

71. Al-Samman, A.M.; Rahman, T.A.; Azmi, M.H.; Al-Gailani, S.A. Millimeter-wave propagation measurements and models at 28 $\mathrm{GHz}$ and $38 \mathrm{GHz}$ in a dining room for $5 \mathrm{G}$ wireless networks. Measurement 2018, 130, 71-81. [CrossRef]

72. Chizhik, D.; Du, J.; Feick, R.; Rodriguez, M.; Castro, G.; Valenzuela, R.A. Path Loss and Directional Gain Measurements at 28 $\mathrm{GHz}$ for non-line-of-sight coverage of indoors with corridors. IEEE Trans. Antennas Propag. 2020, 68, 4820-4830. [CrossRef]

73. Zhu, Y.; Wang, H.; Hong, W.; Dou, J.; Mei, S.; Yuan, X. 28-GHz path-loss measurement and modeling in indoor environments. In Proceedings of the 2015 IEEE 6th International Symposium on Microwave, Antenna, Propagation, and EMC Technologies (MAPE), Shanghai, China, 28-30 October 2015; pp. 234-237.

74. Fan, W.; Carton, I.; Nielsen, J.Ø.; Olesen, K.; Pedersen, G.F. Measured wideband characteristics of indoor channels at centimetric and millimetric bands. EURASIP J. Wirel. Commun. Netw. 2016, 2016, 58. [CrossRef]

75. Salous, S.; Gao, Y. Wideband measurements in indoor and outdoor environments in the $30 \mathrm{GHz}$ and $60 \mathrm{GHz}$ bands. In Proceedings of the 2016 10th European Conference on Antennas and Propagation (EuCAP), Davos, Switzerland, 10-15 April 2016; pp. 1-3. 
76. Al-Samman, A.M.; Rahman, T.A.; Azmi, M.H.; Sharaf, A.; Yamada, Y.; Alhammadi, A. Path loss model in indoor environment at $40 \mathrm{GHz}$ for 5G wireless network. In Proceedings of the 2018 IEEE 14th International Colloquium on Signal Processing \& Its Applications (CSPA), Malaysia, 9-10 March 2018; 2018; pp. 7-12.

77. Zhang, X.; Qiu, G.; Zhang, J.; Tian, L.; Tang, P.; Jiang, T. Analysis of Millimeter-Wave Channel Characteristics Based on Channel Measurements in Indoor Environments at $39 \mathrm{GHz}$. In Proceedings of the 2019 11th International Conference on Wireless Communications and Signal Processing (WCSP), Xi'an, China, 23-25 October 2019; pp. 1-6.

78. Dou, J.; Zhang, N.; Tian, L.; Yang, X.; Yuan, X.; Mei, S.; Wang, H. Propagation channel comparison between 23.5 and 45 GHz in conference scenario. Chin. J. Eng. 2016, 2016. [CrossRef]

79. Xu, H.; Kukshya, V.; Rappaport, T.S. Spatial and temporal characteristics of $60-\mathrm{GHz}$ indoor channels. IEEE J. Sel. Areas Commun. 2002, 20, 620-630. [CrossRef]

80. Peter, W.; Keusgen, W.; Felbecker, R. Measurement and ray-tracing simulation of the $60 \mathrm{GHz}$ indoor broadband channel: Model accuracy and parameterization. In Proceedings of the 2nd European Conference on Antennas and Propagation (EuCAP 2007), EICC, Edinburgh, UK, 11-16 November 2007.

81. Maltsev, A.; Perahia, E.; Maslennikov, R.; Sevastyanov, A.; Lomayev, A.; Khoryaev, A. Impact of polarization characteristics on 60-GHz indoor radio communication systems. IEEE Antennas Wirel. Propag. Lett. 2010, 9, 413-416. [CrossRef]

82. Maltsev, A.; Maslennikov, R.; Sevastyanov, A.; Khoryaev, A.; Lomayev, A. Experimental investigations of 60 GHz WLAN systems in office environment. IEEE J. Sel. Areas Commun. 2009, 27, 1488-1499. [CrossRef]

83. Fryziel, M.; Loyez, C.; Clavier, L.; Rolland, N.; Rolland, P.A. Path-loss model of the 60-GHz indoor radio channel. Microw. Opt. Technol. Lett. 2002, 34, 158-162. [CrossRef]

84. Yang, H.; Herben, M.H.; Smulders, P.F. Impact of antenna pattern and reflective environment on $60 \mathrm{GHz}$ indoor radio channel characteristics. IEEE Antennas Wirel. Propag. Lett. 2005, 4, 300-303. [CrossRef]

85. Lim, C.P.; Lee, M.; Burkholder, R.J.; Volakis, J.L.; Marhefka, R.J. $60 \mathrm{GHz}$ indoor propagation studies for wireless communications based on a ray-tracing method. EURASIP J. Wirel. Commun. Netw. 2007, 2007, 1-6. [CrossRef]

86. Gustafson, C.; Tufvesson, F.; Wyne, S.; Haneda, K.; Molisch, A.F. Directional analysis of measured $60 \mathrm{GHz}$ indoor radio channels using SAGE. In Proceedings of the 2011 IEEE 73rd Vehicular Technology Conference (VTC Spring), Budapest, Hungary, 15-18 May 2011; pp. 1-5.

87. Yang, H.; Smulders; Herben. Indoor channel measurements and analysis in the frequency bands $2 \mathrm{GHz}$ and $60 \mathrm{GHz}$. In Proceedings of the 2005 IEEE 16th International Symposium on Personal, Indoor and Mobile Radio Communications, Berlin, Germany, 11-14 September 2005; Volume 1, pp. 579-583.

88. Kyro, M.; Haneda, K.; Simola, J.; Nakai, K.; Takizawa, K.i.; Hagiwara, H.; Vainikainen, P. Measurement based path loss and delay spread modeling in hospital environments at $60 \mathrm{GHz}$. IEEE Trans. Wirel. Commun. 2011, 10, 2423-2427. [CrossRef]

89. Peter, M.; Wisotzki, M.; Raceala-Motoc, M.; Keusgen, W.; Felbecker, R.; Jacob, M.; Priebe, S.; Kürner, T. Analyzing human body shadowing at $60 \mathrm{GHz}$ : Systematic wideband MIMO measurements and modeling approaches. In Proceedings of the 2012 6th European Conference on Antennas and Propagation (EUCAP), Prague, Czech, 26-30 March 2012; pp. 468-472.

90. Siamarou, A.G.; Al-Nuaimi, M. A wideband frequency-domain channel-sounding system and delay-spread measurements at the license-free 57-to 64-GHz band. IEEE Trans. Instrum. Meas. 2010, 59, 519-526. [CrossRef]

91. Zhang, G.; Saito, K.; Fan, W.; Cai, X.; Hanpinitsak, P.; Takada, J.-i.; Pedersen, G.F. Experimental characterization of millimeter-wave indoor propagation channels at $28 \mathrm{GHz}$. IEEE Access 2018, 6, 76516-76526. [CrossRef]

92. Zhang, G.; Hanpinitsak, P.; Cai, X.; Fan, W.; Saito, K.; Takada, J.i.; Pedersen, G.F. Millimeter-wave channel characterization in large hall scenario at the 10 and $28 \mathrm{GHz}$ bands. In Proceedings of the 2019 13th European Conference on Antennas and Propagation (EuCAP), Krakow, Poland, 31 March-5 April 2019; pp. 1-4.

93. Aborahama, M.; Zakaria, A.; Ismail, M.H.; El-Bardicy, M.; El-Tarhuni, M.; Hatahet, Y. Large-scale channel characterization at 28 GHz on a university campus in the United Arab Emirates. Telecommun. Syst. 2020, 74, 185-199. [CrossRef]

94. Al-Samman, A.M.; Al-Hadhrami, T.; Daho, A.; Hindia, M.; Azmi, M.H.; Dimyati, K.; Alazab, M. Comparative study of indoor propagation model below and above $6 \mathrm{GHz}$ for $5 \mathrm{G}$ wireless networks. Electronics 2019, 8, 44. [CrossRef]

95. Geng, S.; Fan, N.; Zhang, R.; Zhao, X. 28 GHz MIMO Channel Characteristics Analysis for 5G Communication Systems. In Proceedings of the International Conference on 5G for Future Wireless Networks, Beijing, China, 21-23 April 2017; Springer: Berlin/Heidelberg, Germany, 2017; pp. 1-7.

96. Beauvarlet, D.; Virga, K.L. Measured characteristics of 30-GHz indoor propagation channels with low-profile directional antennas. IEEE Antennas Wirel. Propag. Lett. 2002, 1, 87-90. [CrossRef]

97. Beauvarlet, D.; Virga, K.L. Indoor propagation characteristics for wireless communications in the $30 \mathrm{GHz}$ range. In Proceedings of the IEEE Antennas and Propagation Society International Symposium (IEEE Cat. No. 02CH37313), San Antonio, TX, USA, 16-21 June 2002; Volume 1, pp. 244-247.

98. Mohsen, M.; Matolak, D.W. $31 \mathrm{GHz}$ path loss measurement and modeling for indoor/outdoor environments. In Proceedings of the 2018 Wireless Telecommunications Symposium (WTS), Phoenix, AZ, USA, 17-20 April 2018; pp. 1-8.

99. Dupleich, D.; Müller, R.; Skoblikov, S.; Schneider, C.; Luo, J.; Del Galdo, G.; Thomä, R. Multi-band indoor propagation characterization by measurements from 6 to $60 \mathrm{GHz}$. In Proceedings of the 2019 13th European Conference on Antennas and Propagation (EuCAP), Krakow, Poland, 31 March-5 April 2019; pp. 1-5. 
100. Martinez-Ingles, M.T.; Pascual-García, J.; Gaillot, D.P.; Borras, C.S.; Molina-García-Pardo, J.M. Indoor 1-40 GHz channel measurements. In Proceedings of the 2019 13th European Conference on Antennas and Propagation (EuCAP), Krakow, Poland, 31 March-5 April 2019; pp. 1-5.

101. Pascual-García, J.; Martinez-Ingles, M.T.; Gaillot, D.P.; Molina-García-Pardo, J.M.; Egea-López, E. Experimental wireless channel analysis between 1 and $40 \mathrm{GHz}$ in an indoor NLoS corridor environment. In Proceedings of the 2019 International Symposium on Antennas and Propagation (ISAP), Xi'an, China, 27-30 October 2019; pp. 1-3.

102. Yusuf, M.; Tanghe, E.; Martinez-Ingles, M.T.; Pascual-Garcia, J.; Molina-Garcia-Pardo, J.M.; Martens, L.; Joseph, W. FrequencyDependence Characterization of Electromagnetic Reverberation in Indoor Scenarios Based on 1-40 GHz Channel Measurements. IEEE Antennas Wirel. Propag. Lett. 2019, 18, 2175-2179. [CrossRef]

103. Yue, G.; Yu, D.; Qiu, H.; Guan, K.; Yang, L.; Lv, Q. Measurements and Ray Tracing Simulations for Non-Line-of-Sight MillimeterWave Channels in a Confined Corridor Environment. IEEE Access 2019, 7, 85066-85081. [CrossRef]

104. Moraitis, N.; Constantinou, P. Measurements and characterization of wideband indoor radio channel at $60 \mathrm{GHz}$. IEEE Trans. Wirel. Commun. 2006, 5, 880-889. [CrossRef]

105. Choi, M.S.; Grosskopf; Rohde. Statistical characteristics of $60 \mathrm{GHz}$ wideband indoor propagation channel. In Proceedings of the 2005 IEEE 16th International Symposium on Personal, Indoor and Mobile Radio Communications, Berlin, Germany, 11-14 September 2005; Volume 1, pp. 599-603.

106. Hafner, S.; Dupleich, D.A.; Muller, R.; Luo, J.; Schulz, E.; Schneider, C.; Thoma, R.S.; Lu, X.; Wang, T. Characterisation of channel measurements at 70GHz in indoor femtocells. In Proceedings of the 2015 IEEE 81st Vehicular Technology Conference (VTC Spring), Glasgow, UK, 11-14 May 2015; pp. 1-5.

107. Pimienta-del Valle, D.; Hernández-Sáenz, S.; Sáiz-Coronado, P.; Mendo, L.; Garcia-del Pino, P.; Riera, J.M. Indoor Path Loss Measurements at the 5G Millimeter-Wave Bands of 26 and 39 GHz. In Proceedings of the 2019 13th European Conference on Antennas and Propagation (EuCAP), Krakow, Poland, 31 March-5 April 2019; pp. 1-5.

108. Csurgai-Horváth, L.; Horváth, B.; Rieger, I.; Kertész, J.; Adjei-Frimpong, B. Indoor Propagation Measurements for 5G Networks. In Proceedings of the 2018 11th International Symposium on Communication Systems, Networks \& Digital Signal Processing (CSNDSP), Budapest, Hungary, 16-18 July 2018; pp. 1-5.

109. Li, X.; Li, Y.; Li, B. The Diffraction Research of Cylindrical Block Effect Based on Indoor $45 \mathrm{GHz}$ Millimeter Wave Measurements. Information 2017, 8, 50 .

110. Collonge, S.; Zaharia, G.; Zein, G.E. Influence of the human activity on wide-band characteristics of the $60 \mathrm{GHz}$ indoor radio channel. IEEE Trans. Wirel. Commun. 2004, 3, 2396-2406. [CrossRef]

111. Moraitis, N.; Constantinou, P. Indoor channel measurements and characterization at $60 \mathrm{GHz}$ for wireless local area network applications. IEEE Trans. Antennas Propag. 2004, 52, 3180-3189. [CrossRef]

112. Erden, F.; Ozdemir, O.; Guvenc, I. $28 \mathrm{GHz}$ mmWave channel measurements and modeling in a library environment. In Proceedings of the 2020 IEEE Radio and Wireless Symposium (RWS), San Antonio, TX, USA, 26-29 January 2020; pp. 52-55.

113. Chen, X.; Tian, L.; Tang, P.; Zhang, J. Modelling of human body shadowing based on $28 \mathrm{GHz}$ indoor measurement results. In Proceedings of the 2016 IEEE 84th vehicular technology conference (VTC-Fall), Montréal, QC, Canada, 18-21 September 2016; pp. 1-5.

114. Nguyen, S.L.; Jarvelainen, J.; Karttunen, A.; Haneda, K.; Putkonen, J. Comparing radio propagation channels between 28 and 140 GHz bands in a shopping mall. In Proceedings of the 12th European Conference on Antennas and Propagation (EuCAP 2018), London, UK, 9-13 April 2018; pp. 1-5.

115. Matolak, D.W.; Mohsen, M.; Chen, J. Path Loss at $5 \mathrm{GHz}$ and $31 \mathrm{GHz}$ for Two Distinct Indoor Airport Settings. In Proceedings of the 2019 27th European Signal Processing Conference (EUSIPCO), A Coruña, Spain, 2-6 September 2019; pp. 1-5.

116. Lee, J.; Liang, J.; Park, J.J.; Kim, M.D. Directional path loss characteristics of large indoor environments with 28 GHz measurements. In Proceedings of the 2015 IEEE 26th Annual International Symposium on Personal, Indoor, and Mobile Radio Communications (PIMRC), Hong Kong, China, 30 August-2 September 2015; pp. 2204-2208.

117. Kim, M.D.; Liang, J.; Kwon, H.K.; Lee, J. Path loss measurement at indoor commercial areas using 28GHz channel sounding system. In Proceedings of the 2015 17th International Conference on Advanced Communication Technology (ICACT), PyeongChang, Korea, 1-3 July 2015; pp. 535-538.

118. Piesiewicz, R.; Geise, R.; Jacob, M.; Jemai, J.; Kurner, T. Indoor channel measurements of point-to-point ultra broadband short range links between $75 \mathrm{GHz}$ and $110 \mathrm{GHz}$. In Proceedings of the 2008 IEEE Antennas and Propagation Society International, Symposium, San Diego, CA, USA, 5-11 July 2008; pp. 1-4.

119. Malko, A.; Jacob, M.; Piesiewicz, R. W-Band measurements for common buildings materials. In Proceedings of the 2008 International Students and Young Scientists Workshop-Photonics and Microsystems, Wroclaw/Szklarska Poreba, Poland, 20-22 June 2008; pp. 47-49.

120. Talbi, L.; Delisle, G.Y. Indoor radio propagation measurement at $37.2 \mathrm{GHz}$. In Proceedings of the Canadian Conference on Electrical and Computer Engineering, Halifax, NS, Canada, 25-28 September 1994; Volume 2, pp. 681-684.

121. Alsamman, A.M.; Rahman, T.A.; Hindia, M.N.; Nasir, J. Path loss model for indoor emergency stairwell environment at millimeter wave band for 5 G network. Turk. J. Electr. Eng. Comput. Sci. 2018, 26, 3024-3032.

122. Aldhaibani, A.; Rahman, T.A.; Alwarafy, A. Radio-propagation measurements and modeling in indoor stairwells at millimeterwave bands. Phys. Commun. 2020, 38, 100955. [CrossRef] 
123. Al-Saman, A.; Mohamed, M.; Cheffena, M. Radio Propagation Measurements in the Indoor Stairwell Environment at 3.5 and $28 \mathrm{GHz}$ for $5 \mathrm{G}$ Wireless Networks. Int. J. Antennas Propag. 2020, 2020. [CrossRef]

124. Cheffena, M. Industrial wireless communications over the millimeter wave spectrum: opportunities and challenges. IEEE Commun. Mag. 2016, 54, 66-72. [CrossRef]

125. Solomitckii, D.; Orsino, A.; Andreev, S.; Koucheryavy, Y.; Valkama, M. Characterization of mmWave channel properties at 28 and $60 \mathrm{GHz}$ in factory automation deployments. In Proceedings of the 2018 IEEE Wireless Communications and Networking Conference (WCNC), Barcelona, Spain, 15-18 April 2018; pp. 1-6.

126. Zhang, Y.; Wen, J.; Yang, G.; He, Z.; Luo, X. Air-to-air path loss prediction based on machine learning methods in urban environments. Wirel. Commun. Mob. Comput. 2018, 2018. [CrossRef]

127. Alloulah, M.; Huang, H. Future Millimeter-Wave Indoor Systems: A Blueprint for Joint Communication and Sensing. Computer 2019, 52, 16-24. [CrossRef]

128. Yang, G.; Zhang, Y.; He, Z.; Wen, J.; Ji, Z.; Li, Y. Machine-learning-based prediction methods for path loss and delay spread in air-to-ground millimetre-wave channels. IET Microwav. Antennas Propag. 2019, 13, 1113-1121. [CrossRef]

129. Jo, H.S.; Park, C.; Lee, E.; Choi, H.K.; Park, J. Path Loss Prediction based on Machine Learning Techniques: Principal Component Analysis, Artificial Neural Network and Gaussian Process. Sensors 2020, 20, 1927. [CrossRef]

130. Cheng, H.; Ma, S.; Lee, H.; Cho, M. Millimeter Wave Path Loss Modeling for 5G Communications Using Deep Learning with Dilated Convolution and Attention. IEEE Access 2021, 9, 62867-62879. [CrossRef]

131. Venugopal, K.; Heath, R.W. Millimeter Wave Networked Wearables in Dense Indoor Environments. IEEE Access 2016, 4, $1205-1221$. [CrossRef]

132. Johnson, J.E.; Shay, O.; Kim, C.; Liao, C. Wearable Millimeter-Wave Device for Contactless Measurement of Arterial Pulses. IEEE Trans. Biomed. Circ. Syst. 2019, 13, 1525-1534. [CrossRef] [PubMed]

133. Björnson, E.; Özdogan, Ö.; Larsson, E.G. Reconfigurable intelligent surfaces: Three myths and two critical questions. IEEE Commun. Mag. 2020, 58, 90-96. [CrossRef]

134. Ying, X.; Demirhan, U.; Alkhateeb, A. Relay Aided Intelligent Reconfigurable Surfaces: Achieving the Potential Without So Many Antennas. arXiv 2020, arXiv:2006.06644.

135. Ellingson, S.W. Path loss in reconfigurable intelligent surface-enabled channels. arXiv 2019, arXiv:1912.06759.

136. Özdogan, Ö.; Björnson, E.; Larsson, E.G. Intelligent reflecting surfaces: Physics, propagation, and pathloss modeling. IEEE Wirel. Commun. Lett. 2019, 9, 581-585. [CrossRef]

137. Tang, W.; Chen, M.Z.; Chen, X.; Dai, J.Y.; Han, Y.; Di Renzo, M.; Zeng, Y.; Jin, S.; Cheng, Q.; Cui, T.J. Wireless communications with reconfigurable intelligent surface: Path loss modeling and experimental measurement. IEEE Trans. Wirel. Commun. 2021, 20, 421-439. [CrossRef]

138. Di Renzo, M.; Ntontin, K.; Song, J.; Danufane, F.H.; Qian, X.; Lazarakis, F.; De Rosny, J.; Phan-Huy, D.T.; Simeone, O.; Zhang, R.; et al. Reconfigurable intelligent surfaces vs. relaying: Differences, similarities, and performance comparison. IEEE Open J. Commun. Soc. 2020, 1, 798-807. [CrossRef]

139. Pizzo, A.; Marzetta, T.; Sanguinetti, L. Holographic MIMO Communications Under Spatially-Stationary Scattering. arXiv 2020, arXiv:2012.07389.

140. Pizzo, A.; Sanguinetti, L.; Marzetta, T.L. Spatial Characterization of Electromagnetic Random Channels. arXiv 2021, arXiv:2103.15666.

141. Yang, P.; Xiao, Y.; Xiao, M.; Li, S. 6G wireless communications: Vision and potential techniques. IEEE Netw. 2019, 33, 70-75. [CrossRef]

142. David, K.; Berndt, H. 6G vision and requirements: Is there any need for beyond 5G? IEEE Veh. Technol. Mag. 2018, 13, 72-80. [CrossRef]

143. Xing, Y.; Rappaport, T.S. Propagation measurement system and approach at $140 \mathrm{GHz}$-moving to $6 \mathrm{G}$ and above $100 \mathrm{GHz}$. In Proceedings of the 2018 IEEE Global Communications Conference (GLOBECOM), Abu Dhabi, United Arab Emerites, 9-13 December 2018; pp. 1-6.

144. You, X.; Wang, C.X.; Huang, J.; Gao, X.; Zhang, Z.; Wang, M.; Huang, Y.; Zhang, C.; Jiang, Y.; Wang, J.; et al. Towards 6G wireless communication networks: Vision, enabling technologies, and new paradigm shifts. Sci. China Inf. Sci. 2021, 64, 1-74. [CrossRef]

145. Solomitckii, D.; Semkin, V.; Karttunen, A.; Petrov, V.; Nguyen, S.L.H.; Nikopour, H.; Haneda, K.; Andreev, S.; Talwar, S.; Koucheryavy, Y. Characterizing radio wave propagation in urban street canyon with vehicular blockage at $28 \mathrm{GHz}$. IEEE Trans. Veh. Technol. 2020, 69, 1227-1236. [CrossRef]

146. Solomitckii, D.; Semkin, V.; Turunen, M.; Allén, M.; Oestges, C.; Valkama, M. Near-Ground Propagation Measurements for Vehicular Deployments. In Proceedings of the 2021 15th European Conference on Antennas and Propagation (EuCAP), Düsseldorf, Germany, 22-26 March 2021; pp. 1-5.

147. Klaina, H.; Alejos, A.; Aghzout, O.; Falcone, F. Characterization of near-ground radio propagation channel for wireless sensor network with application in smart agriculture. Proceedings 2018, 2, 110. [CrossRef] 